\title{
EXCEDENCIA POR CUIDADO DE HIJOS (O FAMILIARES) EN ESPAÑA E IRLANDA: ANÁLISIS COMPARADO ${ }^{1}$
}

\author{
Patricia Prieto Padín \\ Investiga dora contratada predoctoral FPU del \\ Ministerio de Educación, Cultura y Deporte. \\ Derecho del Trabajo y de la Seguridad Social \\ Universidad de León, España
}

\begin{abstract}
Resumen
El presente estudio pretende identificar (a simple golpe de vista, al tomar cuerpo de cuadro comparativo) las similitudes y las diferencias que la excedencia por cuidado de hijos y familiares presentan en los ordenamientos español e irlandés. Para ello, y después de hacer mención a la evolución normativa de estas figuras conciliatorias en ambos países se procede a analizar las categorías fundamentales que integran su estatuto común, compartido o diferenciado, así como los elementos que carecen de correspondencia, conforme aconsejan los maestros en el análisis comparado del Derecho.
\end{abstract}

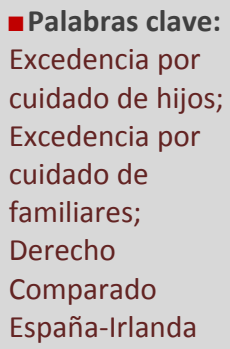

- Keywords:

Parental leave;

Carer's leave;

Comparative law

Spain-Ireland

\begin{abstract}
This study aims to identify (at first sight, because of it takes the shape of a comparison chart) the similarities and differences the leave to care for children and family members have in Spanish and Irish's legal systems. In this sense, and after refering to the regulatory evolution of this conciliatory figures in both countries, the study proceed to analyze the fundamental categories that make up its common statute, shared or differentiated, as well as the elements lacking of correspondence, according advise masters in the comparative analysis of the law.
\end{abstract}

\footnotetext{
${ }^{1}$ Mi agradecimiento sincero al profesor doctor Anthony Kerr, por su acogida en el University College Dublin en el verano de 2015, así como la generosa disponibilidad de las responsables del programa de acogida Srtas. McCabe y Mc Cann por hacer que el trabajo fuera más sencillo. El estudio se enmarca dentro de la actividad del Proyecto Científico: Juventud y Experiencia en el fomento del empleo y del emprendimiento: un reto para Europa y para España. Subproyecto 1: Marco jurídico del empleo de los trabajadores jóvenes, financiado por el Ministerio de Economía y Competitividad (DER 2013-48120-C3$1-\mathrm{P})$.
} 
I. Planteamiento y justificación metodológica - II. Cuadro comparativo - III. Bibliografía

\section{PLANTEAMIENTO Y JUSTIFICACIÓN METODOLÓGICA}

Abordar el estudio comparado de un instituto supone asumir el desafío no sólo de conocer y profundizar en cada uno de los ordenamientos nacionales donde se desarrolla sino de renovar y enriquecer la ciencia, con el convencimiento firme de que permanecer replegado en el sistema propio puede llevar a los juristas a "correr el riesgo de convertirse en simples técnicos, incapaces de dirigir, como es su misión, el desarrollo de su derecho",

La aventura exige cautela; tener presente dos advertencias de quienes fueron maestros en este campo: de un lado, que "el uso del derecho comparado para propósitos prácticos se convertirá en abuso solo si aparece informado por un espíritu que ignore el contexto de la ley"'3; de otro, que nunca cabrá ignorar los datos concretos nacidos de cada norma, a riesgo de convertirla en una reflexión cimiento firme ${ }^{4}$.

Forzosamente habrá lugar, por tanto, a un elemento de tensión, aun doble discurso en el cual, si bien la línea conductora precisará una cuota muy importante de abstracción jurídica sobre los elementos vertebradores, recurriendo a grandes categorías para ofrecer una composición unitaria (con la permeabilidad necesaria, eso sí, a los entornos histórico, institucional económico y social sobre los cuales se asientan), nunca podrá abdicar del esfuerzo por descender a los datos normativos concretos para conferir el necesario realismo, agrupando las muestras obtenidas bajo parámetros homogéneos para, en algunas ocasiones, ofrecer modelos completos; en otras, tan solo, escenas separadas por mor de la estricta peculiaridad derivada de la heterogeneidad de lo regulado o de la diacronía en su desarrollo ${ }^{5}$.

Para presentar los resultados obtenidos de la comparación entre la regulación en España e Irlanda de la excedencia por cuidado de hijos y familiares se ha acudido a cuanto aconsejara con su ejemplo quien tan brillantes páginas ha proporcionado al ordenamiento laboral comparado: un esquema o talla en paralelo que parta de su

${ }^{2}$ DAVID, R. y JAUFFRET-SPINOSI, C.: Los grandes sistemas jurídicos contemporáneos, $11^{\mathrm{a}}$ ed., México (Universidad Nacional), 2010, pág. 8.

3 KAHN-FREUND, O.: "On uses and misuses of comparative law", The Modern Law Review, Vol. 37, núm. 1, 1974, pág. 27.

${ }^{4}$ WEISS, M.: "Convergence and/or divergence in Labor Law systems?: A European perspective”, Comparative Labor Law \& Policy Journal, Vol. 28, 2007, págs. 469-486.

5 OJEDA AVILÉS, A.: Derecho Trasnacional del Trabajo, Valencia (Tirant lo Blanch), 2013, pág. 18. 
historia y fuentes, pase por sus causas, finalidad, dinámica ordinaria y vicisitudes y concluya analizando su extensión y consecuencias ${ }^{6}$.

He aquí el reto y el resultado que se ofrece a la consideración del lector.

\section{CUADRO COMPARATIVO}

\begin{tabular}{|c|c|}
\hline ESPAÑA & IRLANDA \\
\hline \multicolumn{2}{|c|}{ EVOLUCIÓN NORMATIVA } \\
\hline $\begin{array}{l}\text { - Antecedentes remotos: } \\
\text { - Art. } 5 \text { Decreto } 2310 / 70 \text {, de } 20 \text { de agosto, } \\
\text { sobre derechos de la mujer: excedencia } \\
\text { de exclusiva titularidad femenina de un } \\
\text { mínimo de un año y máximo de tres } \\
\text { desde la terminación del descanso por } \\
\text { maternidad con derecho de preferencia } \\
\text { para ser re-contratado cuando se } \\
\text { produjera la primera vacante. } \\
\text { - Art. } 25.4 .2^{\circ} \text { Ley } 16 / 1976 \text {, de } 8 \text { de abril, } \\
\text { de Relaciones Laborales: excedencia para } \\
\text { trabajadoras de hasta tres años desde la } \\
\text { fecha del alumbramiento. } \\
\text { - Precedentes en su sede actual: art. } 46.3 \\
\text { Ley } 8 / 1980, \text { de } 10 \text { de marzo, del Estatuto } \\
\text { de los Trabajadores, extiende a los varones } \\
\text { en igualdad de condiciones un régimen de } \\
\text { excedencia similar a la voluntaria común. } \\
\text { - Art. } 1.3 \text { Ley } 3 / 1989 \text {, de } 3 \text { marzo, } \\
\text { establece distintas medidas en su régimen } \\
\text { destinado a favorecer la igualdad de trato } \\
\text { de la mujer en el trabajo; entre otras, el } \\
\text { derecho a la reserva de puesto de trabajo y }\end{array}$ & $\begin{array}{l}\text { - Antecedentes: } \\
\text { Las medias destinadas a la conciliación de } \\
\text { la vida, personal, familiar y laboral como } \\
\text { un objetivo prioritario del Estado es } \\
\text { relativamente nuevo en Irlanda, pudiendo } \\
\text { situar los orígenes de esta política en la } \\
\text { segunda mitad de la década de } 1990^{7} \text {. De } \\
\text { hecho no es hasta 1998, con la } \\
\text { promulgación de la Parental Leave Act, } \\
1998 \text { (No. 30) cuando se introduce por } \\
\text { primera vez en el ordenamiento irlandés } \\
\text { un derecho legal del empleado (padre o } \\
\text { madre; y, por tanto, diferente de la } \\
\text { protección otorgada con la Maternity } \\
\text { protection Act, } 1994 \text { [No. } 34] \text { ) a ejercer un } \\
\text { permiso o licencia parental no remunerada } \\
\text { de } 14 \text { semanas ( } 3 \text { meses) de duración para } \\
\text { atender al cuidado de los hijos tanto } \\
\text { biológicos como adoptados. El permiso, } \\
\text { que podía disfrutarse en bloque o de forma } \\
\text { fraccionada, debía ejercitarse antes de que } \\
\text { el hijo cumpliera los } 5 \text { años de edad y el } \\
\text { trabajador debía de tener una antigüedad } \\
\text { mínima de un año en la empresa. }\end{array}$ \\
\hline
\end{tabular}

${ }^{6}$ HEPPLE, B.: "The contribution of comparative law to understanding labour relations", en AA.VV. (GORELLI HERNÁNDEZ, J., Dir.): El derecho a la negociación colectiva: "Liber Amicorum" Profesor Antonio Ojeda Avilés, Sevilla (Consejo Andaluz de Relaciones Laborales), 2014, págs. 245 y 246.

7 DALY, M., y CLAVERO, S.: Contemporary Family Policy: A Comparative Review of Ireland, France, Germany, Sweden and the UK, Dublin (Institute of Public Administration), 2002, pág. 4 o NICHOLLS, K.: Europeanizing responses to labor market challenges in Greece, Ireland, and Portugal: the importance of consultative and incorporative policymaking, Tesis doctoral, Indiana (Universidad de Notre Dame), 2007, pág. 191, en http://reality-tape.com/asfalistiko/archives/nicholls.pdf.

${ }^{8}$ El Ministro de Justicia dijo que se había decidido establecer el límite a los cinco "por ser la edad en la que casi todos los niños han empezado la escuela", Seanad Éireann Debate Vol. 155, No. 23, Col. 1409 (12 June 1998), en http://oireachtasdebates.oireachtas.ie/ debates\%20authoring/debateswebpack.nsf/takes/seanad1998061200005?opendocument. 
primer año de excedencia por cuidado de hijos y la extensión del hecho causante del derecho a la a los supuestos de adopción.

- Art. 1 Ley 4/1995, de 23 de marzo, de regulación del permiso parental, incorpora el derecho a la reserva de un puesto de trabajo del mismo grupo profesional o categoría durante el segundo y tercer año; la prohibición de disfrute simultaneo si ambos progenitores trabajan; la imposibilidad de acumulación con sucesivos derechos por nuevos sujetos causantes y el derecho a la asistencia a cursos de formación, a cuya participación deberá ser convocado por el empresario.

- Art. 4 Ley 39/1999, de 5 de noviembre, de conciliación de la vida personal, laboral y familiar, crea una nueva excedencia de duración no superior a un año para atender al cuidado de un familiar, hasta el segundo grado de consanguinidad o afinidad, que por razones de edad, accidente o enfermedad no pueda valerse por sí mismo, y no desempeñe actividad retribuida; extiende el hecho causante del derecho a los supuestos de acogimiento permanente y preadoptivo; reafirma el derecho individual (hombre o mujer) a la excedencia; limita el disfrute simultaneo por razones justificadas de funcionamiento empresarial; incorpora la garantía de indemnidad frente a las represalias discriminatorias por utilización de los derechos de conciliación en los preceptos estatuarios referentes al despido objetivo (art. 53.4. b)) y al disciplinario (art. 55.5 b)).

- Disposición adicional 1ª 3 Ley 40/ 2003, de 18 de noviembre, de Protección a las Familias Numerosas: amplia del período
- Precedentes en su sede actual:

- Art. 2 Parental Leave (Amendment) Act 2006 (No. 13) ${ }^{9}$, introduce las siguientes modificaciones: extiende el límite máximo de edad del hijo a ocho años (16 años si sufre una discapacidad); amplia la licencia parental a las personas que actúan in loco parentis respecto a un hijo; crea la posibilidad de disfrutar el derecho de forma fraccionada, en bloques separados de un mínimo de seis semanas continuas; y la opción de transferir el permiso parental.

- Statutory Instrument 81/2013 European Union -Parental Leave- Regulations $2013^{10}$ : amplía la licencia parental a 18 semanas [4 meses] (art. 4 a)); extiende el hecho causante al supuesto de una "enfermedad a largo plazo" (art. 4 b) e introduce el derecho a solicitar cambios al regreso de un permiso parental (art. 6).

A lo anterior, es imprescindible añadir el derecho del trabajador a un permiso o licencia no remunerada para atender al cuidado familiares y personas en general, al amparo de la Carer's Leave Act, 2001 (No. 21). La principal modificación normativa de este "permiso del cuidador" vino dada por el art. 48 de la Social Welfare Law Reform and Pensions Act 2006 (No. 5) que extendió la duración del derecho conciliatorio de 65 semanas (15 meses) a 104 semanas (24 meses).

9 http://www.irishstatutebook.ie/eli/2006/act/13/enacted/en/pdf. A raíz de las recomendaciones contenidas en el Informe del Grupo de Trabajo sobre la Revisión de la Ley de Licencia Parental 1998 publicado en abril de 2002 (Pn 11.344), en http://www.justice.ie/ en/JELR/reviewparentalleave.pdf/Files/reviewparentalleave.pdf.

10 El Ministro de Justicia e Igualdad, Alan Shatter, firmó, el 8 de marzo de 2013, un Reglamento destinado a enmendar la Ley de Permisos Parentales Irlandesa y dar cumplimiento a las modificaciones requeridas por el nuevo Acuerdo Marco sobre el permiso parental y la subsiguiente Directiva 2010/18/UE, del Consejo, de 8 de marzo de 2010, que aunque debía ser traspuesta a la legislación irlandesa el 8 de marzo de 2012, al Gobierno se le concedió una exención de un año, Statutory Instrument 81/2013 European Union -Parental Leave- Regulations 2013, en http://www.irishstatutebook.ie/eli/2013 /si/81/made/en/pdf. 
de reserva del puesto de trabajo para trabajadores excedentes miembros de una familia numerosa.

- Disposición adicional $1^{a}$ Ley 51/2003, de 2 de diciembre, de Igualdad de Oportunidades, no discriminación y accesibilidad universal de las personas con discapacidad: incluye la discapacidad del familiar como causa autónoma protegida para acceder a la excedencia.

- Disposición adicional 11 $11^{\mathrm{a}} 9$ de la Ley 3/2007, de 22 de marzo, para la Igualdad Efectiva de Mujeres y Hombre: incorpora el acogimiento de naturaleza 'provisional' como supuesto protegido; amplia a dos años la duración de la excedencia por cuidado de familiares y permite el eventual derecho de disfrute fraccionado.

- El Real Decreto Legislativo 2/2015, de 23 de octubre, por el que se aprueba el Texto Refundido de la Ley del Estatuto de los Trabajadores, sustituye "acogimiento, tanto permanente como preadoptivo, aunque éstos sean provisionales" por "guarda con fines de adopción o acogimiento permanente".

\begin{tabular}{|c|c|}
\hline ESPAÑA & IRLANDA \\
\hline \multicolumn{2}{|c|}{ REGULACIÓN ACTUAL } \\
\hline $\begin{array}{l}\text { Está recogido en la norma básica de } \\
\text { regulación de las relaciones de trabajo en } \\
\text { España, concretamente en el apartado } \\
\text { tercero del art. } 46 \text { Estatuto de los } \\
\text { Trabajadores (ET), aprobado por RD } \\
\text { Legislativo } 2 / 2015 \text {, de } 23 \text { de octubre, que } \\
\text { con carácter general regula las excedencias } \\
\text { laborales. Se concibe como una excedencia } \\
\text { especial o cualificada, diferente del resto } \\
\text { (voluntaria ordinaria, sindical, forzosa o de } \\
\text { creación convencional). }\end{array}$ & $\begin{array}{l}\text { Se contempla en una ley destinada } \\
\text { exclusivamente a regular el derecho } \\
\text { conciliatorio. Cabe distinguir distintas } \\
\text { fórmulas }{ }^{11} \text { según se trate de: } \\
\text { - Permiso parental (cuidado de hijos): } \\
\text { Parental Leave Act, } 1998 \text { (No. 30) }{ }^{12} \text { (en } \\
\text { adelante PLA 1998) } \\
\text { - Permiso del cuidador (cuidado de } \\
\text { "personas"): Carer's Leave Act, 2001 } \\
(\text { No. } 21)^{13} \text { (en adelante CLA 2001). }\end{array}$ \\
\hline
\end{tabular}

11 La intención del legislador es, no obstante, consolidar todos los derechos relativos a la conciliación familiar en un único texto legal que ya está siendo redactado (Family Leave Bill) y espera verse aprobado para finales de 2015, IRISH GOVERNMENT: Legislation Programme Spring/Summer Session 2015, enero 2015, en http://www.taoiseach.gov.ie/eng/ Taoiseach_and_Government/Government_Legislation_Programme/Government_Legislative _ Programme_Spring_Summer_2015.pdf.

$12 \mathrm{http}: / /$ www.lawreform.ie/_fileupload/RevisedActs/WithAnnotations/EN_ACT_1998_0030.PDF.

$13 \mathrm{http}: / /$ www.lawreform.ie/_fileupload/RevisedActs/WithAnnotations/EN_ACT_2001_0019.PDF y condiciones resumidas y actualizadas a 22 junio $2015 \mathrm{en} \mathrm{http://www.citizensinformation.ie/}$ en/social_welfare/social_welfare_payments/carers/carers_benefit.html. 
En el art. 237 del nuevo Texto Refundido de la Ley General de la Seguridad Social, aprobado por RD Legislativo $8 / 2015$, de 30 de octubre, existe regulación adicional en torno a las consecuencias y efectos a nivel de Seguridad Social.

Aun cuando esta especial excedencia permite ausentarse del trabajo por un periodo relativamente largo de tiempo para cuidar a hijos o parientes cercanos, no cabe olvidar la existencia de otros derechos conciliatorios a disposición del trabajador, tales como -sin ánimo exhaustivo-: la adaptación de la jornada de trabajo para conciliar (art. 34.8 ET), los permisos laborales del art. 37.3 ET (por razón de matrimonio, nacimiento de hijo, infortunio familiar, traslado de domicilio habitual, exámenes prenatales y técnicas de preparación al parto, adopción o acogimiento); el permiso por maternidad (art. 48 ET) y el permiso por paternidad (art. 48 bis ET); el Permiso de lactancia (37.4 ET); la Reducción de jornada por guarda legal (art. 37.5 ET) o, en fin, los derechos de conciliación extraordinaria recogidos en la negociación colectiva.
Entre los derechos destinados a la conciliación trabajo-familia en Irlanda, cabe destacar el permiso "por fuerza mayor" (art. 13 PLA 1998) que permite ausentarse del trabajo, con derecho a remuneración (durante 3 días en un periodo de 12 meses o 5 días en un periodo de 36 meses) en el supuesto de razones familiares urgentes (lesión o enfermedad de un pariente próximo) que exigen la presencia inmediata e indispensable del trabajador para cuidar a la persona enferma o lesionada.

Una de las ausencias más llamativas entre los derechos de conciliación -a subsanar en los próximos meses ${ }^{14}$ - constituye el hecho de que Irlanda es uno de los países que no garantiza un permiso por paternidad propio para los padres ${ }^{15}$.

\section{ESPAÑA}

IRLANDA

\section{SISTEMA DE FUENTES}

A pesar del enorme poder normativo de los convenios colectivos ${ }^{16}$, en esta especial institución (y ello aunque el legislador realice llamamientos expresos a la negociación colectiva, no solo en el art. 3.1.b) ET, sino también en el concreto art. 46.3 ET, para que desarrolle, complete o concrete determinados aspectos o términos del ejercicio

Según los arts. 4 PLA 1998 y 4 CLA 2001, nada en la ley cabe ser interpretado como una prohibición de su inclusión en un acuerdo de una manera más favorable para el empleado (apartado 3). No obstante, juega también el principio de norma mínima, en el sentido de que, por mor del principio de jerarquía, una disposición en cualquier acuerdo (ya sea un

14 La noticia esperanzadora para muchos padres, en http://www.irishtimes.com/business/ work/fathers-have-their-day-as-paternity-leave-on-the-way-next-year-1.2418335.

15 Junto con Austria, Chipre, República Checa, Alemania, Malta y Eslovaquia, en EUROFOUND: Promoting uptake of parental and paternity leave among fathers in the European Union, Luxemburgo (Oficina de publicaciones de la Unión Europea), 2015, pág. 2, en http://www.cite.gov.pt/pt/destaques/complementosDestqs/Promoting_parental_leave.pdf.

16 FERNÁNDEZ-COSTALES MUÑIZ, J.: "Salud y mujer en la negociación colectiva", en AA.VV. (RODRÍGUEZ ESCANCIANO, S.; MARTÍNEZ BARROSO, M.R. y ÁLVAREZ CUESTA, H., Dirs.): La igualdad por razón de género en los procesos de negociación colectiva: análisis de la situación actual y propuesta de futuro, Pamplona (Aranzadi), 2016, págs. 309-334 (en prensa). 
de los derechos reconocidos a los excedentes por cuidado de hijos o familiares) no tienen demasiada relevancia, pues, pese a encontrar algunas mejoras en ciertos ámbitos, la mayoría de ellos suelen remitir al texto estatutario o lo transcriben (incluso parcialmente, con omisiones graves o sin incluir las correspondientes reformas).

El art. 46.3 ET constituye una norma de derecho necesario relativo que "impide que las partes puedan desarrollarla estableciendo condiciones distintas que perjudiquen al trabajador""17, de ahí que, siguiendo el principio de norma mínima (art. 3.3 ET), una norma laboral no puede empeorar lo previsto en las de mayor rango, debiendo -en todo caso- respetar los mínimos de derecho necesario establecidos en la norma superior. contrato de trabajo o no y si se acuerda antes o después de la aprobación de la ley [apartado 4]) quedará sin efecto si tiene por objeto excluir o limitar la aplicación de cualquier disposición legal o es incompatible con ellas (apartado 1); además, aquella disposición que sea o se vuelva menos favorable para un empleado o en relación con un derecho conferido por ley se debe considerar para ser modificada (apartado 2).

La repercusión de los convenios colectivos es escasa, pues el legislador nacional regula de manera muy exhaustiva el derecho legal; mayor relevancia tiene, en su ordenación concreta, los reglamentos de régimen interior en la empresa ${ }^{18}$. Procede destacar también el papel de las circulares del gobierno para determinado tipo de trabajadores (funcionarios públicos ${ }^{19}$ ) o ámbitos profesionales concretos (enseñanza ${ }^{20}$ o institutos de tecnología ${ }^{21}$, etc.).

17 CORTE HEREDERO, N.: "La atención de las responsabilidades familiares a través de la excedencia laboral: examen del artículo 46.3 del Estatuto de los Trabajadores", Documentación Laboral, núm. 59, 1999, pág. 77.

18 Sirvan de ejemplo, DUBLIN INSTITUTE OF TECHNOLOGY: Parental leave policy \& guidelines, 2015, en http://www.dit.ie/media/humanresources/documents/policiesprocedures/ Parental\%20Leave\%20Policy\%20\&\%20Guidelines\%20-\%20HRP044.pdf; MAYNOOTH UNIVERSITY: Parental \& Force Majeure Leave Scheme, 2013 en https://www. maynoothuniversity.ie/sites/default/files/assets/document/Parental\%20\%26\%20Force\%20Maje ure\%20Leave\%20Scheme\%20-\%20Details_0.pdf.

19 Sirvan de ejemplo, DEPARTAMENT OF PUBLIC EXPENDITURE AND REFORM: Parental Leave in the Civil Service, 2013 en http://circulars.gov.ie/pdf/letter/per/2013/01.pdf o Circular 13/2010: Amendment to Parental Leave Arrangements (age), 2010 en http://circulars.gov.ie/pdf/circular/finance/2010/13.pdf.

20 Referida al permiso parental: DEPARTAMENT OF EDUCATION AND SKILLS: Parental Leave entitlements for registered teachers in recognised Primary and Post Primary Schools (Circular 0026/2013), 2013 en https://www.education.ie/en/Circulars-and-Forms/ActiveCirculars/c10026_2013.pdf, y concerniente al Permiso del Cuidador: DEPARMENT OF EDUCATION AND SCIENCE PRIMARY BRANCH: Carer's Leave for Primary Teachers, 2003 en http://circulars.gov.ie/pdf/circular/education/2003/PC05.pdf, o DEPARTAMENT OF EDUCATION AND SCIENCE: Carer's Leave for Teachers in Second Level Schools, 2003 en http://circulars.gov.ie/pdf/circular/education/2003/PPT17.pdf.

21 DEPARTAMENT OF EDUCATION AND SKILLS: Parental Leave- Amendment for Staff in Institutes of Technology, $2012 \mathrm{en} \mathrm{http://circulars.gov.ie/pdf/circular/education/2012/34.pdf.}$ 


\begin{tabular}{|c|c|}
\hline ESPAÑA & IRLANDA \\
\hline \multicolumn{2}{|c|}{ SITUACIÓN PROTEGIDA } \\
\hline $\begin{array}{l}\text { - Cuidado de hijos: biológicos o adoptivos y } \\
\text { en los supuestos de guarda con fines de } \\
\text { adopción o acogimiento permanente (art. } \\
46.3 .1^{\circ} \text { ET), } \\
\text { - Cuidado de familiares: hasta el segundo } \\
\text { grado de consanguinidad o afinidad, que } \\
\text { por razones de edad, accidente, } \\
\text { enfermedad o discapacidad no pueda } \\
\text { valerse por sí mismo, y no desempeñe } \\
\text { actividad retribuida (art. 46.3.2 ET). } \\
\text { El ordenamiento español es más estricto con } \\
\text { la relación de parentesco que el sistema } \\
\text { irlandés pues este último no establece ningún } \\
\text { límite por vínculo familiar, de modo que } \\
\text { cabe ejercer el derecho no sólo por cualquier } \\
\text { pariente, también por un vecino, amigo o } \\
\text { incluso desconocido, pero, sin embargo, el } \\
\text { legislador español alcanza un nivel menor de } \\
\text { exigencia en las causas que pueden provocar } \\
\text { la situación de excedencia pues contempla } \\
\text { múltiples situaciones mientras que en Irlanda } \\
\text { la persona a cuidar tiene que sufrir } \\
\text { necesariamente una discapacidad y, sobre } \\
\text { todo, el trabajador debe prestar una atención } \\
\text { y cuidado a tiempo completo, obligación que } \\
\text { en España no se exige, en tanto por un lado, } \\
\text { no ha sido establecida tal necesidad de } \\
\text { cuidado, directo, continuo y permanente por } \\
\text { el legislador (de la que por cierto, si hace } \\
\text { alusión el art. } 37.5 .3^{\circ} \text { ET) y por otro lado, el } \\
\text { máximo intérprete de la ley, ha disipado } \\
\text { cualquier duda, cuando ha dado por supuesta } \\
\text { la compatibilidad entre trabajo por cuenta } \\
\text { ajena o actividad profesional por cuenta } \\
\text { propia con esta especial excedenciaa }\end{array}$ & $\begin{array}{l}\text { - Cuidado de hijos biológicos o adoptivos } \\
\text { (art. } 6.1 \text { PLA 1998). } \\
\text { - Cuidado de "personas": El art. 6.1 CLA } \\
2001 \text { impone dos requisitos que delimitan } \\
\text { el ámbito subjetivo del sujeto causante o } \\
\text { persona a cuidar, en el sentido de que debe } \\
\text { cumplir con la condición de "relevant } \\
\text { person" y ha de necesitar "full-time care } \\
\text { and attention". El significado, por } \\
\text { remisión de la propia ley, lo recoge el art. } \\
\text { 82.A Social Welfare Act, 2000, sin } \\
\text { perjuicio de que el Ministro competente } \\
\text { pueda dictar reglamentos que especifican } \\
\text { estas circunstancias y condiciones. } \\
\text { - El concepto de "Relevant person" o } \\
\text { "persona relevante" hace referencia a } \\
\text { aquella (no siendo perceptora de un } \\
\text { aumento de la pensión de invalidez en } \\
\text { virtud del art. } 57 \text { en relación con la } \\
\text { asistencia constante) tiene una } \\
\text { discapacidad tal que requiere cuidado y } \\
\text { atención a tiempo completo, y que, } \\
\text { además,: a) Ha alcanzado la edad de } 16 \\
\text { años }{ }^{23} \text { o b) Es menor de } 16 \text { años pero } \\
\text { recibe un subsidio para la atención } \\
\text { domiciliaria de los niños discapacitados } \\
\text { bajo el art. } 61 \text { Health Act, 1970. } \\
\text { - "Full-time care and attention" o } \\
\text { "atención y cuidado a tiempo completo" } \\
\text { implica que la "persona relevante": a) } \\
\text { Tiene una discapacidad (cuya naturaleza } \\
\text { y alcance ha sido certificada por un } \\
\text { médico) y requiere el cuidado de otra } \\
\text { persona porque; b) necesita una } \\
\text { supervisión continua y la asistencia } \\
\text { frecuente a lo largo del día en relación a } \\
\text { las funciones corporales normales, y, c) } \\
\text { requiere una supervisión continua con el } \\
\text { fin de evitar un peligro para ella misma. }\end{array}$ \\
\hline
\end{tabular}

22 STS 10 febrero 2015 (Rec. 25/2014).

23 LAW SOCIETY OF IRELAND (MOFFATT, J., Ed.): Employment Law, $3^{\text {a }}$ ed., Oxford (Oxford University Press), 2011, pág. 149 y FAULKNER, M.: Essentials of Irish Labour Law, $2^{\mathrm{a}}$ ed., Dublin (Gill \& Macmillan), 2013, pág. 141, sitúan la edad en 18 años. 


\section{ESPAÑA}

\section{DURACIÓN DEL DERECHO, LÍMITE Y HORQUILLA TEMPORAL}

- Cuidado de hijos: 3 años, a contar desde la fecha de nacimiento o, en su caso, de la resolución judicial o administrativa de adopción (art. 46.3.1 $1^{\circ} \mathrm{ET}$ )

- Cuidado de familiares: 2 años (art. 46.3.2 ${ }^{\circ}$ ET) sin límite temporal de ejercicio de acreditar el resto de los requisitos.

En ambas modalidades no existe obligación de iniciar la excedencia necesariamente a partir de una determinada fecha y tampoco hay inconveniente en disfrutar del derecho conciliatorio por un periodo temporal inferior al máximo legal, sin embargo, mientras que en la excedencia por cuidado de familiares la ley únicamente fija un límite máximo de duración; para el supuesto de excedencia por cuidado de hijos, el legislador fija una "fecha de caducidad" 24 de forma que el periodo de duración que no se disfrute dentro de ese periodo máximo -computado desde el nacimiento o resolución judicial o administrativa de adopción-, se consume.
- Cuidado de hijo: 18 semanas [4 meses] (art. 6.1 PLA 1998) considerando los problemas de derecho transitorio ${ }^{25}$ hasta que el hijo cumpla 8 años (art. 6.2. a) PLA 1998).

- Irlanda ha optado por acoger la duración mínima que fija la cláusula 2.2 de la Directiva 2010/18/UE, del Consejo, de 8 de marzo de 2010 y la diferencia con el "permiso parental" español es notable, de ahí que más bien parezca una extensión del permiso de maternidad (paternidad si lo hubiera) y no una verdadera excedencia, según se conoce en España.

- Cuidado de personas: 104 semanas [2 años] (art. 6.1 CLA 2001). La ley afirma expresamente que el derecho podrá ejercitarse "en cualquier momento" (art. 6.4 CLA 2001). Existe, no obstante, un periodo de disfrute mínimo, pues el empresario puede denegar, basándose en motivos razonables $\mathrm{y}$ en todo caso justificados, aquellos permisos cuya duración de disfrute sea inferior a 13 semanas (art. 8.2 CLA 2001). A pesar de este límite legal nada impide que las partes lleguen a un acuerdo para ejercer el permiso del cuidador por un periodo temporal menor a 13 semanas.

24 RODRÍGUEZ ESCANCIANO, S.: "La excedencia por razones familiares: una realidad jurídica necesitada de mayor protección social", Anuario da Facultade de Dereito da Universidade da Coruña, núm. 11, 2007, pág. 865.

25 Para algunos no está demasiado claro, http://www.labourlawnetwork.eu/ national_labour_law/national_legislation/legislative_developments $/ \mathrm{prm} / 109 / \mathrm{v}$ _detail $/ \mathrm{id}$ 2946/category_17/index.html, y para otros no parece haber especial impedimento http://circulars.gov.ie/pdf/circular/hse/2013/06.pdf en dilucidar si los padres trabajadores que ya han disfrutado (total o parcialmente) de permiso parental de acuerdo con la anterior regulación (antes del 8 marzo 2013, entrada en funcionamiento del Reglamento que extendió a 18 semanas), tienen derecho a tomar las cuatro semanas adicionales (o periodo que reste a sumar al ya disfrutado) siempre que no se vulneren los requisitos legales referidos al umbral de edad u opere el límite de recuperación de la enfermedad o discapacidad del hijo. Mayor enjundia presentan aquellos supuestos en los cuales se pretende disfrutar las cuatro semanas adicionales (o más, si sólo se ha disfrutado parte) y el trabajador ha cambiado de empleo, pero todavía no cumple el año de antigüedad requerido, máxime cuando la edad máxima del hijo esté próxima a la prevista como límite. 


\begin{tabular}{|c|c|}
\hline \multicolumn{2}{|c|}{\begin{tabular}{c|c} 
ESPAÑA & IRLANDA \\
REQUISITOS DEL SUJETO CAUSANTE
\end{tabular}} \\
\hline \multicolumn{2}{|c|}{ REQUISITOS DEL SUJETO CAUSANTE } \\
\hline $\begin{array}{l}\text { - Cuidado de hijo (art. } 46.3 .1^{\circ} \text { ET): } \\
\text { - Biológicos: edad máxima de } 3 \text { años. } \\
\text { - Supuestos de adopción o acogimiento: el } \\
\text { límite no opera de forma tan estricta, pues } \\
\text { los } 3 \text { años de disfrute se computan desde la } \\
\text { resolución judicial o administrativa. } \\
\text { - Cuidado de familiar (art. } 46.3 .2^{\circ} \text { ET): cumplir } \\
\text { con el grado de parentesco (hasta el segundo } \\
\text { grado de consanguinidad o afinidad), no } \\
\text { desempeñar actividad retribuida y no poder } \\
\text { valerse por sí mismo por razón de edad, } \\
\text { accidente, enfermedad o discapacidad. } \\
\text { Aunque este es un tema polémico, la } \\
\text { consideración más acorde con los derechos } \\
\text { del empleado y del menor pasaría por } \\
\text { reconocer cómo nada impide que, por el } \\
\text { mismo sujeto causante, y por razón de la } \\
\text { corta edad, pueda el mismo trabajador } \\
\text { solicitar consecutiva o alternativamente a la } \\
\text { excedencia por cuidado de hijo, otra para } \\
\text { cuidado de familiar }{ }^{26} \text {. }\end{array}$ & $\begin{array}{l}\text { - Cuidado de hijos: } \\
\text { - Biológicos: Hasta que el hijo cumpla } 8 \\
\text { años (art. 6.2. a) PLA 1998). } \\
\text { - Supuesto de adopción: si en la fecha de } \\
\text { la adopción el hijo ha alcanzado la edad } \\
\text { de } 6 \text { años, pero no más de } 8 \text {, el permiso } \\
\text { puede disfrutarse dentro de los dos años } \\
\text { siguientes desde de la orden de } \\
\text { adopción. } \\
\text { - Cuidado de personas: Cumplir las condi- } \\
\text { ciones de "Relevant person" y "Full-time } \\
\text { care and attention" anteriormente especifi- } \\
\text { cadas. } \\
\text { Tal y como está configurado el permiso del } \\
\text { cuidado en la Carer's Leave Act, } 2001 \text { (No. } \\
\text { 21), al trabajador se le impediría disfrutar de } \\
\text { este permiso para cuidar a un hijo menor (por } \\
\text { razón de la edad). }\end{array}$ \\
\hline
\end{tabular}

26 Reconociendo esta posibilidad, bajo el argumento de que, "aun cuando una primera lectura del precepto podría hacernos pensar que los sujetos causantes del derecho a la excedencia son distintos en ambos supuestos: el hijo recién nacido (menor de tres años), adoptado o acogido, en la excedencia regulada en el párrafo primero, y otro familiar, enfermo o desvalido, en el segundo, sin embargo una interpretación literal $\mathrm{y}$, fundamentalmente, teleológica del precepto nos lleva a considerar que en los dos casos subyace una situación de desvalimiento de la persona causante del ejercicio del derecho, motivada por su edad, enfermedad o accidente, de tal forma que no existe obstáculo alguno para permitir el disfrute de la excedencia solicitada por el demandante, pues un niño mayor de tres años es, sin duda, un familiar que por razón de edad no puede valerse por sí mismo" [STSJ Navarra 23 febrero 2006 (Rec. 25)]. En sentido contrario, aunque reconociendo que el límite temporal para la excedencia por cuidado de hijo "puede mostrarse insuficiente para conciliar la vida laboral y familiar" [SSTSJ País Vasco 2 mayo 2007 (Rec. 424) o Aragón 14 octubre 2009 (Rec. 737)], al sostener que "no es dable soslayar este límite acudiendo a la excedencia (por cuidado de familiares) cuando se trate de un hijo (...) de cinco años de edad, que no consta que esté enfermo, accidentado ni discapacitado, puesto que, a tenor de la exposición de motivos de la norma que la introdujo, esta excedencia tiene por objeto "ocuparse de personas mayores y enfermas, en línea con los cambios demográficos y el envejecimiento de la población"; igualmente STSJ Castilla y León/Burgos 23 octubre 2015 (Rec. 649) o, en fin, misma consideración respecto del límite de edad previsto para la reducción de jornada por cuidado de hijo [STSJ Cataluña 23 julio 2003 (Rec. 8289/2002)]. 


\begin{tabular}{|c|c|}
\hline ESPAÑA & IRLANDA \\
\hline \multicolumn{2}{|c|}{$\begin{array}{l}\text { HIJOS DISCAPACITADOS O CON ALGÚN TIPO DE ENFERMEDAD A LARGO } \\
\text { PLAZO }\end{array}$} \\
\hline $\begin{array}{l}\text { En la excedencia por cuidado de hijos no se } \\
\text { establece una ampliación adicional si el } \\
\text { menor sufre algún tipo de discapacidad o } \\
\text { enfermedad a largo plazo; no obstante, nada } \\
\text { impide que, pasado el periodo de excedencia } \\
\text { por cuidado de hijo, el trabajador se pueda } \\
\text { acoger a una excedencia por cuidado de } \\
\text { familiar cuando, por razón de la } \\
\text { discapacidad o la enfermedad a largo plazo } \\
\text { no pueda valerse por sí mismo y además } \\
\text { cumpla el resto de requisitos. }\end{array}$ & $\begin{array}{l}\text { A efectos del permiso parental, si el menor } \\
\text { necesitado de cuidado sufre algún tipo de } \\
\text { discapacidad }{ }^{27} \text { o padece una enfermedad a } \\
\text { largo plazo }{ }^{28} \text { se aplica un límite de edad } \\
\text { superior al establecido con carácter general } \\
\text { de } 8 \text { años. La caducidad del derecho se sitúa } \\
\text { en el momento en que cese la situación } \\
\text { impeditiva de discapacidad o enfermedad o, } \\
\text { en todo caso, el cumplimiento de } 16 \text { años } \\
\text { (art. 6.2. c) PLA 1998). } \\
\text { Sin perjuicio de esta ampliación, parece } \\
\text { que nada impide al trabajador solicitar un } \\
\text { permiso al amparo de la Carer's Leave Act, } \\
\text { 2001 (No. 21) para cuidar a su hijo } \\
\text { discapacitado (no en el supuesto de } \\
\text { enfermedad a largo plazo) cuando acredite } \\
\text { los requisitos legales para ello. }\end{array}$ \\
\hline
\end{tabular}

\begin{tabular}{|c|c|}
\hline ESPAÑA & IRLANDA \\
\hline \multicolumn{2}{|c|}{ DIVERSIDAD DE MODELOS DE FAMILIA } \\
\hline $\begin{array}{l}\text { - Familias numerosas: El legislador establece } \\
\text { una mejora, a efectos de ampliar la reserva } \\
\text { del mismo puesto de trabajo del excedente, si } \\
\text { el empleado es miembro de una familia } \\
\text { numerosa, distingüendo aquella que tiene } \\
\text { carácter general o especial. } \\
\text { - Familias monoparentales: El legislador no } \\
\text { establece mejora alguna al respecto de este } \\
\text { tipo de familia; sin embargo, cabe mencionar } \\
\text { que alguna regulación autonómica sí ha } \\
\text { tenido en cuenta la monoparentalidad a } \\
\text { efectos de la concesión de ayudas y } \\
\text { subvenciones, en el sentido de excluir del } \\
\text { régimen de concesión de concurrencia } \\
\text { competitiva la solicitud en favor de la } \\
\text { resolución siguiendo el orden de presenta- }\end{array}$ & $\begin{array}{l}\text { La normativa no establece referencia alguna } \\
\text { respecto a las familias numerosas, no } \\
\text { obstante, si hace una alusión indirecta a la } \\
\text { monoparentalidad al mencionar a la persona } \\
\text { que tienen la condición de "relevant parent" en } \\
\text { más de una capacidad con respecto a un hijo, es } \\
\text { decir, cuando un trabajador desempeña más de } \\
\text { un rol o función respecto de un menor (en el } \\
\text { caso de familia monoparental la persona asume } \\
\text { el papel de padre y de madre o, en el caso de } \\
\text { una custodia de abuelos, el abuelo o abuela } \\
\text { desarrollan también la función de padre o } \\
\text { madre, etc.). } \\
\text { El legislador no hace ninguna referencia a las } \\
\text { parejas de hecho y ello pese a que respecto } \\
\text { de la licencia por fuerza mayor, reconozca } \\
\text { como sujeto causante a quien reside con el }\end{array}$ \\
\hline
\end{tabular}

27 Definida en la propia ley (art. 6.9 PLA 1998) como "deterioro perdurable en la salud física, sensorial, mental o intelectual del niño de tal manera que el nivel de atención requerido para el niño es sustancialmente mayor que el que generalmente se requiere para los niños de la misma edad que no tienen tal deterioro".

28 Incluida por el Reglamento de 2013 y definida por el mismo a efectos del permiso parental como "una enfermedad cuyo efecto es que el nivel de atención requerido para el niño es sustancialmente mayor al nivel de atención que el que generalmente se requiere para los niños de la misma edad que no tienen cualquier enfermedad a largo plazo" (art. 6.9 PLA 1998). 
ción o para incrementar la cuantía de la subvención $^{29}$.

- Parejas de hecho: Conforme a la redacción de la ley (susceptible de mejora por convenio) se negaría el derecho al disfrute de la excedencia por cuidado de familiares para atender a la pareja de hecho (o incluso al ex cónyuge cuando el vínculo matrimonial se hubiera disuelto por nulidad o divorcio). empleado en una relación de dependencia doméstica, incluyendo parejas del mismo sexo [art. 13.2 f) PLA 1998].

\begin{tabular}{|c|c|}
\hline ESPAÑA & IRLANDA \\
\hline \multicolumn{2}{|c|}{ TITULARIDAD DEL DERECHO: TRABAJADOR } \\
\hline $\begin{array}{l}\text { Esta especial excedencia constituye un } \\
\text { derecho individual del trabajador hombre o } \\
\text { mujer (art. } 46.3 \text { ET). } \\
\text { La normativa estatal española no requiere una } \\
\text { antigüedad mínima para ejercer el derecho, con } \\
\text { ello cabe constatar como el legislador de } \\
\text { manera indirecta ha querido tener en cuenta a } \\
\text { los trabajadores temporales o de duración } \\
\text { determinada, pues independientemente de las } \\
\text { dificultades prácticas que tienen para disfrutar } \\
\text { de la excedencia por motivos familiares, de } \\
\text { ellos también cabe predicar su derecho sin más } \\
\text { limitación que la propia vigencia del contrato } \\
\text { temporal. La inclusión en convenio colectivo de } \\
\text { la exigencia de una determinada antigüedad, } \\
\text { llevaría a considerar dicha cláusula como nula y } \\
\text { sin efecto, máxime cuando el art. 15.6 ET } \\
\text { proclama que los trabajadores con contratos } \\
\text { temporales y de duración determinada tendrán } \\
\text { los mismos derechos que los trabajadores con } \\
\text { contratos de duración indefinida. }\end{array}$ & $\begin{array}{l}\text { El permiso parental es un derecho individual } \\
\text { del trabajador hombre o mujer, no obstante, } \\
\text { la ley regula ciertas peculiaridades con } \\
\text { respecto a la titularidad: } \\
\text { - Antigüedad mínima: Aunque el legislador } \\
\text { irlandés reconoce expresamente que los } \\
\text { trabajadores a tiempo parcial, los contratados } \\
\text { de duración determinada o temporales y los } \\
\text { sujetos a un contrato de formación, también } \\
\text { tienen pueden disfrutar del permiso parental } \\
\text { (art. 2.1 PLA 1998), no obstante, en } \\
\text { consonancia con la letra b) de la cláusula } \\
\text { tercera de la Directiva 2010/18/UE, del } \\
\text { Consejo, de } 8 \text { de marzo de } 2010 \text {, supedita el } \\
\text { derecho al cumplimiento de una determinada } \\
\text { antigüedad, es decir "empleo continuo o } \\
\text { continuado"30 en la empresa, demandando } \\
\text { al empleado haber estado trabajando al } \\
\text { menos un año en la empresa de solicitar el } \\
\text { permiso parental (art. } 6.3 \text { PLA 1998) o } 12 \\
\text { meses de antigüedad si se pretende ejercer el } \\
\text { permiso del cuidador (art. } 6.1 \text { CLA 2001). }\end{array}$ \\
\hline
\end{tabular}

29 El análisis exhaustivo en AGRA VIFORCOS, B.: "Principales Líneas programáticas y normativas diseñadas en la Comunidad Autónoma de Castilla y León para la tutela de las situaciones de monoparentalidad", Revista de Investigación Económica y Social de Castilla y León, núm. 11, 2008, pág. 185 en http://dialnet.unirioja.es/servlet/articulo?codigo= 2737160; "Algunos interrogantes sobre las familias numerosas", Conferencia en el Primer Foro Nacional de Familias Monoparentales, 2010 en http://isadoraduncan.es/files/File/Interrogantes _Beatriz_Agra.pdf, o "Dificultades para la integración laboral de las familias monoparentales", en AA.VV.(RODRÍGUEZ ESCANCIANO, S. y MARTÍNEZ BARROSO, M. R., Dirs. y ÁLVAREZ CUESTA, H., Coord.): La inserción de las mujeres en riesgo de exclusión social, Valencia (Tirant lo Blanch), 2015, págs. 95 y ss.

30 Término que bien pudiera llevar a equívoco de no haber mediado la actuación legislativa a definir tal concepto, en el sentido de apuntar que incluye el empleo completado por un trabajador bajo dos o más contratos de duración determinada con el mismo empleador (art. 6.9 F8 PLA 1998). 
La figura irlandesa del "relevant parent", como extensión del derecho a todas las personas que actúan en el lugar de los padres respecto de un hijo ("in loco parentis"), queda salvada o compensada en España con la alusión a los casos de adopción y acogimiento, e incluso cuando el trabajador ejercita el derecho conciliatorio respecto de sus parientes hasta el segundo grado por consanguinidad o afinidad.

En ninguno de los ordenamientos no existe ningún problema para disfrutar este derecho cuando el otro cónyuge no trabaja, limitación que si ha sido incluida en otros ordenamientos europeos $\mathrm{y}$ ha sido recientemente considerada contraría tanto a la directiva europea sobre el permiso parental como a la directiva europea relativa a la aplicación del principio de igualdad de oportunidades e igualdad de trato entre hombres y mujeres en asuntos de empleo y ocupación ${ }^{31}$.
Esta exigencia legal (relevante en aquellos casos en los que el trabajador cambia de empleo o tiene un contrato temporal, máxime si la edad del hijo está próxima al límite legal) se atenúa, no obstante, en el caso del permiso parental, pues si el hijo está muy cerca del umbral de edad máximo para poder disfrutar del permiso parental y además, el trabajador tiene, en todo caso, una antigüedad mínima de 3 meses en la empresa, se podrá disfrutar de un permiso parental prorrateado, a saber: una semana por cada mes de antigüedad completado al inicio del derecho conciliatorio (art. 7 PLA 1998).

- Otras personas: El legislador extiende el derecho conciliatorio a las personas que actúan en lugar de los padres con respecto a un niño ("in loco parentis"), es decir, "relevant parent", sabiendo que aquella persona con más de un rol o función con respecto a un niño (familia monoparental [padre y madre], custodia de abuelos [padre y abuelo]....) no tendrá derecho a un permiso parental en más de un rol o función en relación con el niño (art. 6.5 PLA).

31 Declarando que se opone a las directrices europeas, la normativa nacional de Grecia en virtud de la cual se priva a un funcionario del derecho a un permiso parental si su esposa no ejerce una actividad laboral o profesional, salvo que, debido a dolencia o enfermedad grave, se la considere incapacitada para hacer frente a las necesidades de cuidado del hijo, STJUE 222/14, de 16 julio 2015, asunto Konstantinos Maïstrellis. 


\begin{tabular}{|c|c|}
\hline ESPAÑA & IRLANDA \\
\hline \multicolumn{2}{|c|}{ REMUNERACIÓN } \\
\hline $\begin{array}{l}\text { El Estado no garantiza una protección social } \\
\text { efectiva en términos económicos para ejercer } \\
\text { esta especial excedencia pues los } \\
\text { trabajadores no disponen de una renta } \\
\text { sustitutiva a los salarios dejados de percibir } \\
\text { por tener que abandonar de manera temporal } \\
\text { el empleo para cuidar a los hijos y/o } \\
\text { familiares. Nada impide que se establezca } \\
\text { una ayuda por convenio colectivo para cubrir } \\
\text { esta necesidad. } \\
\text { En el ámbito autonómico, y al amparo de la } \\
\text { competencia exclusiva en materia de } \\
\text { asistencia social (art. 148.1.20 CE), es } \\
\text { posible encontrar (en tiempos de crisis } \\
\text { económicas y recortes sociales en menor } \\
\text { medida) alguna ayuda o subvención econó- } \\
\text { mica }{ }^{33} \text { destinada a paliar los efectos que esta } \\
\text { excedencia provoca. }\end{array}$ & $\begin{array}{l}\text { Aunque ha sido un tema polémico en } \\
\text { Irlanda } 34 \text {, la ley irlandesa no prevé ningún } \\
\text { tipo de compensación económica para el } \\
\text { trabajador que disfruta de este derecho } \\
\text { conciliatorio. } \\
\text { El papel del Estado Irlandés como garante de } \\
\text { protección social únicamente se prevé o } \\
\text { subyace en esta materia en relación con el } \\
\text { "Carer's Leave" o "Permiso del cuidador", } \\
\text { de tal forma que cuando el trabajador } \\
\text { abandona temporalmente el empleo (máximo } \\
104 \text { semanas) con el fin de prestar } \\
\text { asistencia/cuidado a tiempo completo a una o } \\
\text { más personas que necesitan atención, el } \\
\text { gobierno otorga una especie de subsidio } \\
\text { económico "Carer's Benefit"35 o "Beneficio } \\
\text { del Cuidador", cuyo solicitud y régimen es } \\
\text { independiente (diferentes requisitos) al }\end{array}$ \\
\hline
\end{tabular}

32 La denuncia pública de esta carencia y sus problemas accesorios, caben observarlos en el Informe de la Subcomisión creada en el seno de la Comisión de Igualdad para el estudio de la Racionalización de Horarios, la Conciliación de la Vida Personal, Familiar y Laboral y la Corresponsabilidad (BOCG Congreso de los Diputados, Serie D, núm. 330, de 26 septiembre 2013, pág. 67).

Véase, por ejemplo, la convocatoria de ayudas económicas directas de pago periódico por excedencia para el cuidado de hijos e hijas menores de edad y para el cuidado de familiares de primer grado mayores de edad que requieran la necesidad de su cuidado directo, continuo y permanente, por enfermedad y/o accidente sobrevenido, para $2015 \mathrm{del}$ Gobierno de Navarra (BO Navarra, núm. 57, de 25 marzo 2015).

34 Mientras que el Ministro de Justicia, Igualdad y Reforma Legislativa (Mr. O'Donoghue) explicó como la decisión de no remunerar este permiso se había basado en la intención de no perjudicar ni a los empresarios (costo adicional al reemplazo de esa persona y efecto dañino para la posición competitiva de Irlanda), ni tampoco al Ministerio de Hacienda (desembolso de cerca de 40 millones al año solo en prestaciones sociales) Seanad Éireann Debate Vol. 155, No. 23, Col. 1409 (12 June 1998) en http://oireachtasdebates. oireachtas.ie/debates\%20authoring/debateswebpack.nsf/takes/seanad1998061200005?ope ndocument; con posterioridad en el Informe sobre la revisión de la Ley de Permiso Parental, se examina la cuestión de proporcionar un pago en estos casos, analizando al detalle los siguientes parámetros: a) La falta de pago afecta a la comprensión de la licencia parental; b) Grado en el que el permiso está siendo adoptado en periodos fraccionados; c) Costo para los empleadores; d) Costo para los empleados y sus hijos; e) Costo para la Caja de Seguro Social / Ministerio de Hacienda; f) Costo para los empleadores del sector público; g) ¿Quién debe pagar? -Los empleadores o la Caja de Seguro Social / Ministerio de Hacienda; h) Pago adecuado- Ganancias relacionadas o pago a tanto alzado, e i) La situación comparativa en los Estados miembros de la UE, GOVEMMENT OF IRELAND, PROGRAMME FOR PROSPERITY AND FAIRNESS: Report of the working group review of the Parental Leave Act 1998, Dublin, Stationery Office, 2002, en http://www.justice.ie/en/JELR/reviewparentalleave.pdf/Files/review parentalleave.pdf. 
Aunque observando el esquema irlandés del "Carer's Benefit" o "Beneficio del Cuidador" bien podría imaginarse establecer una relación con la protección dispensada a nivel estatal por el ordenamiento bajo la Ley de 39/2006, de 14 de diciembre, de promoción de la autonomía personal y atención a las personas en situación de dependencia (arts. 14. 4 y 18) y más concretamente al amparo del Real Decreto $615 / 2007$, de 11 de mayo, por el que se regula la Seguridad Social de los cuidadores de las personas en situación de dependencia, cierto es que la cobertura dispensada entre una y otra figura es completamente diferente, pues mientras que en Irlanda se otorga una prestación económica al cuidador, en España la Ley de Dependencia concede la ayuda a la persona dependiente, pero no a su familia ni a los cuidadores. Estos últimos, únicamente tienen la opción (carácter voluntario) de suscribir un convenio especial para, en su caso, con la obligación de abonar a su cargo exclusivo, las cuotas correspondientes, recibir el beneficio de generar, mantener o ampliar, en determinadas situaciones, el derecho a las prestaciones de la Seguridad Social, concretamente y en virtud del art. 3 RD 615/2007, de 11 de mayo, para ser considerado en "situación de asimilación al alta (...) a efectos de las prestaciones de jubilación y de incapacidad permanente y muerte $y$ supervivencia, derivadas de accidente, cualquiera que sea su carácter, o de enfermedad, con independencia de su naturaleza"(excluido el desempleo). contenido a nivel laboral en la CLA 2001, pero cuyo esquema es indudablemente diseñado para ser ejercitado en tándem ${ }^{36}$.

En virtud del art. 6.7 CLA 2001, y para evitar dudas, se declara que el derecho al "Carer's Benefit" o "Beneficio del Cuidador" no es una condición para tener derecho a la licencia o permiso del cuidador que permite la suspensión del contrato de trabajo.

35 Toda la información detallada en http://www.citizensinformation.ie/en/social_welfare/ social_welfare_payments/carers/carers_benefit.html. Es importante no confundirlo con el "Carer's Allowance" o "Subsidio del Cuidador" http://www.citizensinformation.ie/ en/social_welfare/social_welfare_payments/carers/carers_allowance.html, pues mientras que el primero es un pago del seguro social hecho a alguien que abandona el trabajo para cuidar a una persona incapacitada, el segundo no está conectado con el mundo laboral en tanto constituye un pago a personas de bajos ingresos que están cuidando a una persona incapacitada.

36 DALY, M., y CLAVERO, S.: Contemporary family police in Ireland and Europe, Dublin (Department of Social and Family Affairs), 2002, en http://www.welfare.ie/en/downloads/ cfpreport.pdf, pág. 58 . 


\begin{tabular}{|c|c|}
\hline ESPAÑA & IRLANDA \\
\hline \multicolumn{2}{|c|}{ FRACCIONAMIENTO } \\
\hline $\begin{array}{l}\text { El derecho a disfrutar esta excedencia de } \\
\text { forma fraccionada, es decir, "por tramos } \\
\text { inferiores, aunque sean varios y separados"37, } \\
\text { se contempla expresamente como una posi- } \\
\text { bilidad en la ley (art. } 46.3 \mathrm{ET} \text { ), no obstante } \\
\text { habrá que atender, en cada caso, al acuerdo } \\
\text { con el empresario o a lo que disponga el } \\
\text { convenio colectivo pues la ley guarda } \\
\text { silencio al respecto. }\end{array}$ & $\begin{array}{l}\text { En virtud del art. } 7.1 \text { PLA } 1998 \text {, la licencia } \\
\text { parental puede ser disfrutada como un bloque } \\
\text { continúo de } 18 \text { semanas o en } 2 \text { períodos } \\
\text { separados, cada uno compuesto por no menos } \\
\text { de } 6 \text { semanas y sin exceder del total de } 18 \text {, } \\
\text { siempre que antes de disfrutar de la segunda } \\
\text { parte hayan transcurrido al menos } 10 \text { semanas } \\
\text { (salvo pacto en contra más favorable) desde la } \\
\text { finalización de la primera. }\end{array}$ \\
\hline $\begin{array}{l}\text { El texto estatutario no contempla expresamente } \\
\text { que la excedencia por motivos familiares pueda } \\
\text { disfrutarse a tiempo parcial (tal y como si lo ha } \\
\text { hecho para la maternidad/paternidad (D.A. } 1^{\text {a }} \\
\text { RD } 295 / 2009 \text {, de } 6 \text { de marzo, por el que se } \\
\text { regulan las prestaciones económicas del sistema } \\
\text { de la Seguridad Social por maternidad, } \\
\text { paternidad, riesgo durante el embarazo y riesgo } \\
\text { durante la lactancia natural), razón por la cual } \\
\text { hay que entender que el legislador acoge } \\
\text { únicamente el disfrute de este derecho a } \\
\text { jornada completa y sin ninguna modalidad } \\
\text { adicional, sin perjuicio, obviamente de la } \\
\text { reducción de jornada por cuidado de menores y } \\
\text { otros familiares (art. } 37.5 \mathrm{ET} \text { ). }\end{array}$ & $\begin{array}{l}\text { Por acuerdo entre empresario y trabajador }{ }^{38} \\
\text { (o sus representantes), el permiso parental } \\
\text { puede tomarse de forma flexible, es decir por } \\
\text { periodos cortos (o trabajando horas reducidas } \\
\text { hasta el límite de las } 18 \text { semanas), compren- } \\
\text { diendo cada bloque: } \\
\text { - Uno o más días en que el empleado, a pesar } \\
\text { de la licencia, estaría trabajando en el } \\
\text { empleo en cuestión (similar a la formula } \\
\text { "keeping-in-touch (KIT) days", de UK }{ }^{39} \text { o } \\
\text { North Ireland }{ }^{40} \text { ). } \\
\text { - Una o más horas durante las cuales, a pesar } \\
\text { de la licencia, el empleado estaría } \\
\text { trabajando en el empleo de que se tratara } \\
\text { (análogo a la reducción de jornada). }\end{array}$ \\
\hline
\end{tabular}

37 STSJ Murcia 12 marzo 2001(Rec. 1080/2000).

38 La opción de tomar el permiso parental en días libres o en forma de reducción de horas (a tiempo parcial), no es un derecho legal para los empleados a menos que el empleador esté de acuerdo, Tribunal de Apelaciones de Empleo; Caso O'Neill - $v$ - Dunnes Stores, 1 marzo 2000 (ELR 306).

39 The Maternity and Parental Leave etc. and the Paternity and Adoption Leave (Amendment) Regulations 2006 introdujo esta fórmula en el permiso por maternidad (creando el art. 12 A the Maternity and Parental Leave etc. Regulations 1999) y en el permiso por adopción (creando el art. 21 A The Paternity and Adoption Leave, 2002), en virtud de la cual (a excepción, en el caso del permiso por maternidad, de las dos primeras semanas obligatorias desde el nacimiento), un empleado puede llevar a cabo a cabo un máximo de 10 días de trabajo para su empleador durante su período de licencia legal, sin implicar por ello la terminación de dicho permiso, pero tampoco la ampliación de la duración total del derecho de conciliación, consciente, en todo caso, de que esta posibilidad no confiere, por sí misma, ningún derecho sobre un empleador para exigir que cualquier trabajo se lleve a cabo durante el período de licencia, ni ningún derecho del empleado a trabajar durante la misma. http://www.legislation.gov.uk/uksi/2006/2014/ regulation/9/made.

40 The Maternity and Parental Leave etc. (Amendment) Regulations (Northern Ireland) 2006 introdujo la misma disposición en el permiso por maternidad, creando el art. 12 A. The Maternity and Parental Leave etc. Regulations (Northern Ireland) 1999, http://www.legislation.gov.uk/nisr/2006/372/regulation/10/made. 


\begin{tabular}{|l|l|}
\hline & $\begin{array}{l}\text { Con más detalle, los apartados 2, 3 y } 4 \text { del } \\
\text { art. 7.2 a) PLA 1998, establecen fórmulas } \\
\text { para el cálculo de este derecho. }\end{array}$ \\
& $\begin{array}{l}\text { El permiso del cuidador también permite ser } \\
\text { tomado en un bloque continuo de } 104 \text { semanas } \\
\text { o en una serie de periodos cuya duración } \\
\text { agregada no exceda del total máximo (art. 8.1 } \\
\text { CLA 2001), sabiendo que, en este último caso, } \\
\text { entre los periodos de permiso disfrutados debe } \\
\text { haber un espacio temporal de al menos seis } \\
\text { semanas (art. 8.3 CLA 2001). }\end{array}$ \\
\hline
\end{tabular}

\begin{tabular}{|c|c|}
\hline ESPAÑA & IRLANDA \\
\hline \multicolumn{2}{|c|}{ NATURALEZA CAUSAL: ABUSO DE DERECHO } \\
\hline $\begin{array}{l}\text { No hay duda de que la mejor atención del } \\
\text { hijo o familiar constituye la finalidad y, a su } \\
\text { vez, comporta el elemento causal del } \\
\text { derecho conciliatorio, no obstante, la } \\
\text { normativa española no exige una dedicación } \\
\text { total, directa e ininterrumpida a tal tarea, ni } \\
\text { tampoco impone una limitación especial al } \\
\text { desarrollo de otra actividad durante el } \\
\text { disfrute de la excedencia. } \\
\text { En este contexto, la viabilidad de que quien } \\
\text { solicita una excedencia para este fin pueda } \\
\text { dedicarse en ese tiempo a una ocupación } \\
\text { distinta (y acompañada del adjetivo ulterior, } \\
\text { pues la compaginación con una situación de } \\
\text { pluriempleo previa parece indiscutible }{ }^{41} \text { ) ha } \\
\text { llevado a interpretaciones abiertamente } \\
\text { contradictorias en los Tribunales Superiores } \\
\text { de Justicia }{ }^{42} \text { (también en lo que respecta a la } \\
\text { reducción de jornada por motivos familiares }{ }^{43} \text { ). }\end{array}$ & $\begin{array}{l}\text { En el art. } 12 \text { PLA } 1998 \text { el legislador irlandés } \\
\text { recuerda el carácter causal del derecho y } \\
\text { advierte de las consecuencias de un posible } \\
\text { abuso, pues está sujeto a la condición de que } \\
\text { se utilice para cuidar efectivamente al hijo } \\
\text { por el que se solicita el permiso } 44 \text {. Se } \\
\text { diferencian dos potestades al empresario: } \\
\text { - Facultad para terminar el disfrute del } \\
\text { derecho (ante tempus): Concediendo } \\
\text { grandes facultades a la parte empresarial, } \\
\text { el legislador determina que "cuando el } \\
\text { empleador tiene motivos razonables para } \\
\text { creer que el permiso parental no se utiliza } \\
\text { con el propósito de cuidar el hijo (objeto } \\
\text { fundamental y exclusivo), éste puede } \\
\text { ordenar el cese del trabajador en su } \\
\text { disfrute". }\end{array}$ \\
\hline
\end{tabular}

41 Reconociendo el derecho de la trabajadora excedente en un trabajo a tiempo parcial a percibir prestación por desempleo tras la extinción del contrato de trabajo a tiempo completo, STSJ Madrid 10 junio 2003 (Rec. 2637/2003).

42 Un análisis exhaustivo en PRIETO PADÍN, P.: "Excedencia por cuidado de hijos y familiares: compatibilidad con el trabajo por cuenta propia o ajena y competencia desleal", RTSS (CEF), núm. 391, 2015, págs. 101-132.

43 Manteniendo una posición contraria a la compatibilidad de la reducción de jornada con otra prestación de servicios, SSTSJ Cataluña 7 enero 2014 (Rec. 4777/2013) o Canarias/ Las Palmas 31 enero 2012 (Rec. 1532/2011), incluso por apreciar concurrencia desleal [STSJ Galicia 20 febrero 2013 (Rec. 5760/2012)]; sin embargo, sopesando que la reducción de jornada cumple las funciones típicas para las que fue creada pese a su situación de pluriempleo, STSJ Baleares 8 octubre 2009 (Rec. 436).

44 De forma similar ocurre en el Reino Unido, pues el art. 17 the Maternity and Parental Leave etc. Regulations 1999, advierte sobre cómo un empleado que disfruta de una licencia de maternidad o permiso parental [e idéntica clausula respecto al licencia por paternidad y el permiso de adopción, ex arts. 12.1 b) y 21.b) The Paternity and Adoption Leave Regulations 2002], debe, durante ese periodo, por su obligación implícita de buena fe en relación con 
Polémica -suscitada también en el ámbito doctrinal-, que ha sido recientemente resuelta por el Tribunal Supremo, al dar por supuesta la compatibilidad entre excedencia y trabajo, afirmando que "en la medida en que el nuevo trabajo resulta compatible con el cuidado del menor, no se le deben anudar a la legítima aspiración de la madre trabajadora de obtener algunos ingresos -que ha dejado de obtener precisamente por la excedencia para el cuidado de hijos- unas consecuencias tan negativas" 45 como la pérdida del derecho a reserva de su puesto de trabajo o la consideración como situación asimilada al alta a efectos del reconocimiento de prestaciones de Seguridad Social.

Faltaría conocer el parecer judicial del máximo intérprete de la ley respecto de una práctica negocial cada días más extendida, que sanciona categóricamente el simple hecho de "realizar trabajos remunerados por cuenta ajena o habituales por cuenta propia, ${ }^{46} \mathrm{o}$, en su caso, trata de aquilatar el concepto de competencia desleal precisamente en relación con el tiempo de excedencia estableciendo diversas consecuencias que van desde la consideración de voluntaria a todos los efectos, pasando por la pérdida del derecho al reingreso automático o de otras mejoras establecidas en convenio, hasta la extinción definitiva de la relación laboral, o incluso entendiéndose como una baja o renuncia voluntaria del empleado.
Los únicos condicionantes exigidos son que el empresario notifique al trabajador afectado, con un mínimo de 7 días de antelación, su intención de poner fin al permiso por razón del abuso y, además, que tal escrito contenga una declaración en forma de resumen sobre los motivos de la decisión (art. 11. 3 PLA 1998).

El empleado en cuestión debe regresar a su trabajo en el día especificado en la notificación (art. 12. 3 PLA 1998), sabiendo que el periodo de tiempo que oscila entre la fecha de terminación por esta causa (ante tempus) y la fecha de terminación ordinaria y que figuraba en el escrito de confirmación, no se considera permiso parental.

- Facultad para denegar la concesión del derecho ( $a b$ initio/ $a b$ origine): Instada la solicitud de permiso parental por el trabajador, el empresario puede tomar la decisión de denegar la concesión del permiso parental si tiene motivos razonables para creer que aquel no tiene derecho (art. 12. 4 PLA 1998). El único condicionante exigido es que el empresario, en el escrito de contestación, avale o justifique su decisión negativa poniendo de manifiesto una declaración en forma de resumen sobre los motivos de la decisión (art. 12.5 PLA 1998).

Además, en ambos casos, el legislador exige una fase de pliego de cargos y descargos (art. 12.6 PLA 1998), por consiguiente, antes de la notificación definitiva del empleador decidiendo sobre la terminación o denegación del permiso parental, debe comunicar por escrito al trabajador su intención/propuesta al efecto, exponiendo los motivos concretos; circunstancia ante la cual aquel podrá presentar alegaciones (dentro de los 7 días siguientes a la recepción de la comunicación).

su empleador, atender a los requerimientos relativos a: preaviso de la terminación de su contrato de trabajo, divulgación de información confidencial, aceptación de regalos $\mathrm{u}$ otros beneficios o, en fin, la participación en cualquier otro empleo o negocio. http://www.legislation.gov.uk/uksi/1999/3312/regulation/17/made. Y en Irlanda del Norte http://www.legislation.gov.uk/nisr/1999/471/regulation/17/made.

45 STS 10 febrero 2015 (Rec. 25/2014).

46 Art. 45.2 CC Altcam Automotive, SL i Altcam Valls, S.L.U del centre de treball de Valls (BOP Tarragona núm. 365, de 19 marzo 2014) o art. 37 CC Ara Vinc, S.L. (BOP Barcelona núm. 22, de 3 febrero 2014)]. 
La solución debiera pasar por considerarlas nulas y sin efecto, pues son previsiones limitativas de derechos que se subsanan por ministerio de la ley. En otro caso, si la limitación conllevará alguna compensación, la respuesta legal sería considerarla en todo caso como una excedencia ad nutum al amparo del art. 46.6 ET "otros supuestos colectivamente acordados, con el régimen y efectos que se prevean", es decir, constituyendo otro tipo distinto, alternativo $\mathrm{y}$ compatible con la excedencia reconocida a nivel estatutario, que en cuanto tal, se mantiene como opción o derecho distinto al cual puede acogerse el trabajador.
Los avisos deberán ser conservados por ambas partes (art. 12.7 PLA 1998).

Respecto al permiso del cuidador, esta limitación también está presente al recoger expresamente el legislador que el derecho conciliatorio no puede compaginarse en modo alguno con el desarrollo de otro empleo o autoempleo [art. 6.1. d) Leave Act, 2001], pues constituye causa de terminación del permiso del cuidador [art. 11.2 c) Leave Act, 2001].

Sin perjuicio de esta limitación, existe una excepción, por cuanto el requisito para proporcionar una atención a tiempo completo se evaluará de forma individual por el Departamento de Protección Social, pudiendo el trabajador: a) asistir a un curso de educación o formación o aceptar un trabajo voluntario o comunidad de hasta 15 horas por semana; b) participar en el autoempleo, siempre que lo desarrolle en su propia casa y no sobrepase un límite de ingresos establecido en los reglamentos elaborados por el Ministerio de Protección Social, c) desempeñar un empleo fuera del hogar, previa aprobación por el Ministro de Asuntos Sociales y siempre que no sobrepase las 15 horas por semana ${ }^{47}$.

En este sentido, parece que no se pretende ni se desea que el empleado sujeto al permiso de cuidador proporcione la atención durante las 24 horas del día, puesto que la prohibición de trabajo y exigencia de atención a tiempo completo se aplican de manera flexible por el Departamento de la Protección Social, considerando tanto las necesidades de los empleados que brindan la atención, como de la persona lo recibe.

En fin, también cabe destacar incidencias relacionadas con la buena fe en los permisos por fuerza mayor ${ }^{48}$.

47 DEPARTAMENT OF JOBS, ENTERPRISE AND INNOVATION: Carer's Leave Act, 2001. Explanatory Booklet for Employers and Employees, Dublin, 2011, en https://www.workplacerelations.ie/en/Publications_Forms/Guide_to_the_Carers_Leave Act.pdf, pág. 6. Además, existen otras reglas adicionales para recibir el "Carer's Benefit, concretamente que las ganancias netas ingresadas por esta actividad laboral no excedan de 332,50 € por semana. (después de haber deducido de impuestos y Universal Cargo Social, PRSI, jubilación (pago de pensiones), recaudación de pensiones, cuotas sindicales y las suscripciones a mutualidades de su salarial total), http://www.citizensinformation.ie/en/ social_welfare/social_welfare_payments/carers/carers_benefit.html.

Considerando el carácter "urgente", "inmediato" e "indispensable" que exige la ley para su disfrute, existen de un lado: fallos judiciales que avalan la decisión del empleado de ausentarse del trabajo para cuidar a su hija afectada de un sarpullido en las piernas aunque en el examen médico posterior se diagnostique una erupción menor [High Court, 24 enero 2001 (Carey v Penn Racquet Sports)], atender a su pareja aquejada de gripe [Employment Appeals Tribunal, 9 febrero 2009 (PL2/2010)] o velar por su hija que, pese a estar 


\begin{tabular}{|c|c|}
\hline ESPAÑA & IRLANDA \\
\hline REQUISITOS FORMALES PARA EJERCER EL DERECHO: COMUNICACIÓN \\
DEL TRABAJADOR \\
\hline
\end{tabular}

La ley no exige al trabajador que comunique por escrito su intención de ejercer el derecho conciliatorio, no obstante, resulta conveniente (e incluso cabría considerarla una obligación que dimana de la buena fe) notificar al empresario de tal extremo. De esta manera, y siguiendo los términos que el legislador si contempla en el art. 37.6 ET para la concreción horaria y la determinación del periodo de disfrute del permiso de lactancia y reducción de jornada, sería aconsejable con un mínimo de 15 días de antelación e indicando la duración prevista y la fecha de inicio y finalización del derecho conciliatorio.

Los convenios colectivos, en concordancia con los arts. 82 y 85.1 ET y art. 37.1 CE y en coherencia con el principio de complementariedad, pueden y suelen establecer determinados matices o condicionantes que, aun no estando previstos en la norma básica, son oportunos, o al menos sin ilegalidad aparente para completar los criterios generales del texto estatutario $\mathrm{y}$, sobre todo porque queridos $\mathrm{y}$ aceptados por las partes, proporcionan mayor seguridad jurídica al empleado que quiera acogerse a esta especial excedencia.

Cuando el trabajador pretende el disfrute de un permiso parental debe presentar a su empleador una solicitud por escrito y firmada tan pronto como sea razonablemente posible; en todo caso, con al menos 6 semanas de antelación a la fecha inicial prevista para su disfrute (art. 8.1 PLA 1998). En esta notificación se debe especificar la fecha de comienzo del derecho, la duración y la manera en que se propone disfrutar la licencia parental (por ejemplo, fraccionada) (art. 8.2 PLA 1998). Esta exigencia conlleva carios aspectos jurídicamente relevantes como:

- “Arrepentimiento del trabajador": Antes de producirse la fecha de inicio de la licencia parental solicitada, el empleado puede revocar, mediante escrito dirigido al empresario, su intención de acogerse al derecho (art. 8.3 PLA 1998).

- Incumplimiento plazo: Cuando la solicitud no cumple el plazo mínimo exigido de preaviso (6 semanas), el empresario puede, a su discreción, conceder el permiso parental con todos los efectos recogidos en la ley (art. 8.4 PLA 1998).

- Copia al trabajador: El empleador debe conservar el escrito de solicitud sobre el permiso parental y entregar una copia al trabajador (art. 8.5 PLA 1998).

enferma, no consta atención medica de doctor u otro profesional sanitario [Employment Appeals Tribunal, 23 septiembre 2009 (PL2/2009)]; de otro lado, pronunciamientos que no encuentran adecuada la conducta del trabajador por cuanto ante el estado febril del hijo y la imposibilidad de conseguir cita médica para ese día, proporciona la atención en casa y acude al médico al día siguiente [Employment Appeals Tribunal, 20 mayo 2011 (PL1/2010)], no existe prueba evidente de atención o visita médica [Employment Appeals Tribunal, 7 septiembre 2012 (PL2/2011)], o en fin, a pesar de esgrimir el estado febril de su esposa y la necesidad de cuidar a sus hijos (uno de ellos con autismo), consta una petición anterior del trabajador para ausentarse del trabajo ese día en cuestión (denegada por la empresa) que coincidía con la Final de la Liga de Campeones de la UEFA [Employment Appeals Tribunal, 23 septiembre 2013 (PL1/2012)]. 
De este modo, no es raro encontrar la exigencia de comunicación escrita a la empresa, tanto para ejercer o iniciar el derecho como para terminarlo y regresar al trabajo (algunos agentes negociadores diseñan incluso el propio modelo de comunicación formal) o la imposición de determinados plazos de preaviso, o en fin, la demanda de justificación de la excedencia en términos de acreditar el vínculo de parentesco, discapacidad, etc.

En cuanto a la eventual petición de anulación del trabajador del disfrute del derecho, la ley guarda silencio, no obstante, parece que esta pretensión podría colisionar con los intereses de la empresa en tanto "una vez concedida la excedencia por el periodo solicitado, tiene derecho a poder organizar sus propios intereses en función del periodo por el que el trabajador optó, y ese derecho quebraría si tuviera que someterse a variaciones ulteriores unilateralmente decididas por el trabajador excedente" 49 .
- Prueba datos sobre el hijo causante: El empresario puede requerir al trabajado la aportación de pruebas oportunas que evidencien razonablemente su legítimo derecho al permiso parental (art. 8.6 PLA 1998), tales como: a) fecha del nacimiento del hijo a cuidar, b) condición de padre relevante (orden de adopción...), o c) naturaleza de la discapacidad del hijo.

- Permiso fraccionado: La notificación de quien pretende disfrutar un permiso parental fraccionado puede tratarse como (art. 8.7 PLA 1998): a) Un aviso, si el empleado ha notificado una vez su derecho especificando los dos periodos de permiso parental; b) Dos avisos, si el empleado ha notificado dos veces su derecho indicando en cada uno, el periodo de permiso parental.

Por el contrario, cuando la intención es hacer uso de un permiso del cuidador, el trabajador primeramente, debe instar una solicitud al Ministro de Protección Social para que dictamine una decisión teniendo en cuenta la 'persona relevante' (arts. 6.5 y 6.6 CLA 2001). El Ministro puede regular algún aspecto sobre la forma en que el permiso ha de ser disfrutado si se ejerce en varios periodos de tiempo (art. 8.6 CLA 2001).

En segundo lugar, el trabajador debe notificar esta intención al empresario en un plazo de al menos 6 semanas de antelación a la fecha inicial prevista de disfrute (art. 9.1 CLA 2001), salvo en caso de circunstancias excepcionales o de emergencia que lo impida, donde la notificación debe cursarse tan pronto como sea razonablemente posible (art. 9.2 CLA 2001). En esta propuesta de permiso se debe especificar la fecha de comienzo del derecho y la manera en que se propone disfrutar la licencia parental (en bloque o fraccionada), así como que la solicitud preceptiva al Ministro se ha efectuado y ya se ha recibido respuesta (art. 9.1 CLA 2001). Esta exigencia conlleva carios aspectos jurídicamente relevantes como:

49 Alegación de la empresa, ratificada por el Tribunal, ante la solicitud de reincorporación del trabajo tras haber fallecido el sujeto que recibía el cuidado, STSJ Madrid 6 octubre 2011 (Rec. 824/2011). 


\begin{tabular}{|l|l|}
\hline & $\begin{array}{l}\text { "Arrepentimiento del trabajador": Antes de } \\
\text { producirse la fecha de inicio del permiso } \\
\text { de cuidador, el empleado puede revocarlo, } \\
\text { mediante escrito dirigido al empresario } \\
\text { (art. 9.3 CLA 2001). } \\
\text { - Incumplimiento plazo: Cuando la solicitud } \\
\text { no cumple el plazo mínimo exigido de } \\
\text { preaviso (6 semanas), el empresario puede, } \\
\text { a su discreción, conceder el permiso } \\
\text { parental con todos los efectos recogidos en } \\
\text { la ley (art. 9.4 CLA 2001). } \\
\text { - El empleador debe conservar todos los } \\
\text { documentos entregados por el trabajador en } \\
\text { la solicitud del permiso (art. 9.5 CLA 2001). }\end{array}$ \\
\hline
\end{tabular}

\begin{tabular}{|c|c|}
\hline ESPAÑA & IRLANDA \\
\hline \multicolumn{2}{|c|}{$\begin{array}{l}\text { REQUISITOS FORMALES PARA EJERCER EL DERECHO: CONTESTACIÓN } \\
\text { DEL EMPRESARIO }\end{array}$} \\
\hline $\begin{array}{l}\text { El legislador configura esta especial } \\
\text { excedencia como un auténtico derecho } \\
\text { subjetivo, por lo que en modo alguno su } \\
\text { reconocimiento tiene un carácter graciable o } \\
\text { discrecional }^{50} \text {, así "la empresa, está obligada } \\
\text { a conceder la excedencia y debe hacerlo sin } \\
\text { dilaciones arbitrarias"51. } \\
\text { En ocasiones, se observa que los convenios } \\
\text { colectivos demandan una contestación escrita } \\
\text { por parte del empresario como requisito sine } \\
\text { qua non para iniciar el disfrute de este derecho } \\
\text { conciliatorio, sin embargo, esta exigencia } \\
\text { parece desvirtuarse si lo pretendido es aplazar } \\
\text { el derecho pues sería contradictorio que } \\
\text { "esperar obtener respuesta empresarial de la } \\
\text { solicitud pueda privar al trabajador de un } \\
\text { derecho reconocido por la ley" } \text { ". }\end{array}$ & $\begin{array}{l}\text { Instada la solicitud del permiso, el } \\
\text { empresario está obligado a considerar y } \\
\text { responder a tal petición en un plazo que no } \\
\text { ha de retrasarse de las } 4 \text { semanas anteriores } \\
\text { al comienzo del disfrute si lo solicitado es el } \\
\text { permiso parental (art. 9.1 PLA 1998) o de } 2 \\
\text { semanas si se pretende el permiso del } \\
\text { cuidador (art. 10.1 CLA 2001). Si el } \\
\text { trabajador ha incumplido el preaviso } \\
\text { preceptivo de } 6 \text { semanas, y el empleador } \\
\text { acepta considerar la solicitud, tan pronto } \\
\text { como sea posible (arts. 9.2 PLA o 10.1 CLA } \\
\text { 2001). } \\
\text { En esta notificación, firmada por el } \\
\text { empleador, debe constar, al igual que lo } \\
\text { reflejó el trabajador en la solicitud, la fecha } \\
\text { de comienzo del derecho, la duración y la } \\
\text { manera en que la licencia se disfrutará (arts. } \\
\text { 9.1 PLA 1998 10.1 CLA 2001) } \\
\text { El empresario ha de conservar tal escrito de } \\
\text { confirmación (firmado por el trabajador } \\
\text { afectado) y entregar una copia al trabajador, } \\
\text { quien también tiene el deber de conservarlo } \\
\text { (arts. 9.3 PLA 1998 o 10.3 CLA 2001). }\end{array}$ \\
\hline
\end{tabular}

50 "No depende de la voluntad de la empresa [sino que, por el contrario] opera automáticamente sin más requisito que la previa comunicación al empresario", STSJ Comunidad Valenciana 30 julio 1996 (Rec. 2601/1995).

51 SSTSJ Madrid 10 enero 2002 y 29 abril 2003 (Rec. 5205/2001 y 327).

52 STSJ País Vasco 9 diciembre 2014 (Rec. 2367). 


\begin{tabular}{|c|c|}
\hline ESPAÑA & IRLANDA \\
\hline \multicolumn{2}{|c|}{$\begin{array}{l}\text { APLAZAMIENTO O DENEGACIÓN DEL DERECHO POR PARTE DEL } \\
\text { EMPRESARIO }\end{array}$} \\
\hline $\begin{array}{l}\text { Admitiendo que la excedencia se configura } \\
\text { legalmente como un auténtico derecho del } \\
\text { trabajador y que "la protección de la familia } \\
\text { y la infancia es la finalidad que debe } \\
\text { prevalecer y servir de orientación para } \\
\text { solucionar cualquier duda interpretativa,53, } \\
\text { los únicos motivos que pudieran estar } \\
\text { justificados para negar o aplazar el pase a la } \\
\text { situación conciliatoria vienen dados: de un } \\
\text { lado, por la no justificación de los requisitos } \\
\text { exigidos para su ejercicio, de otro lado, y } \\
\text { siempre que obedezcan a razones de } \\
\text { funcionamiento empresarial, cuando la } \\
\text { pretensión se curse, para cuidar al mismo } \\
\text { causante, por dos o más trabajadores de la } \\
\text { misma empresa (art. 46.3 ET). } \\
\text { Frente a la eventual oposición empresarial } \\
\text { (expresa o tácita) para disfrutar del derecho } \\
\text { conciliatorio, la solución ofrecida al } \\
\text { trabajador se sitúa no sólo en impugnar tal } \\
\text { decisión ante el orden jurisdiccional social } \\
\text { (cuyo procedimiento será urgente y se le dará } \\
\text { tramitación preferente, art. 139 LJS); } \\
\text { también es factible recurrir a la vía de hecho } \\
\text { de auto tutela del propio derecho }{ }^{54} \text {, y en } \\
\text { consecuencia, adoptar unilateralmente la } \\
\text { decisión de autoconcederse dicha situación } \\
\text { de excedencia sin que, posteriormente, pueda } \\
\text { alegarse faltas injustificadas de asistencia al } \\
\text { trabajo. }\end{array}$ & $\begin{array}{l}\text { - Aplazamiento: } \\
\text { En virtud del art. 11.1 PLA 1998, instada la } \\
\text { solicitud de permiso parental (y salvo que ya } \\
\text { exista un documento de confirmación del } \\
\text { derecho, firmado por ambas partes, art. } 11.5 \\
\text { PLA 1998), el empresario puede tomar la } \\
\text { decisión de posponer su inicio si está } \\
\text { convencido de que su disfrute en el periodo } \\
\text { acordado va a tener un importante efecto } \\
\text { negativo sobre el funcionamiento de su } \\
\text { negocio. El precepto enumera las causas } \\
\text { concretas en virtud de las cuales cabe aplazar } \\
\text { el derecho conciliatorio } 55 \text {; a saber: variaciones } \\
\text { estacionales en el volumen de trabajo, falta de } \\
\text { disponibilidad de una persona para llevar a } \\
\text { cabo las funciones del empleado que se acoge } \\
\text { al permiso parental, naturaleza de esas } \\
\text { funciones (difícil cobertura del puesto), el } \\
\text { número de empleados que tienen derecho a } \\
\text { disfrutar del permiso parental en el mismo } \\
\text { periodo o, en fin, cualquiera otras cuestiones } \\
\text { relevantes. } \\
\text { Es condición sine qua non que, antes de } \\
\text { notificar el aplazamiento propuesto, el } \\
\text { empresario consulte con el empleado tal } \\
\text { decisión (art. } 11.2 \text { PLA 1998). } \\
\text { Efectuada la consulta, el aplazamiento debe } \\
\text { ser notificado al trabajador con al menos } 4 \\
\text { semanas de antelación al comienzo previsto } \\
\text { para el disfrute del derecho y la medida no } \\
\text { puede exceder a } 6 \text { meses, a contar -salvo }\end{array}$ \\
\hline
\end{tabular}

53 STS 20 julio 2000 (Rec. 3799/1999) sobre la elección de turno o STSJ Baleares 8 octubre 2009 (Rec. 436).

54 Defendiendo esta flexible solución, pues "los límites de la autotutela de los derechos del trabajador, han de hacerse compatibles con la existencia del derecho mismo, que dejaría de existir si la empresa pudiera arbitrariamente negarlo mediante una conducta dilatoria (...); y por otra parte la prohibición de la autotutela de los derechos ha de hacerse compatible también con el estado de necesidad como excusa absolutoria", STSJ Navarra 4 mayo 2006 (Rec. 87).

55 Se corresponden exactamente con los motivos que ejemplificaba la Directiva 96/34/CE, del Consejo, de 3 de junio de 1996, cuya letra e) de la Cláusula segunda, preveía que los Estados Miembros, a través de ley o de convenio colectivo, podían definir las circunstancias que permitiesen a un empleador posponer el permiso parental. Enumeración, que de manera llamativa, la nueva Directiva 2010/18/UE del Consejo de 8 de marzo de 2010 suprimió. 
pacto en contra- desde la fecha de inicio de disfrute especificada por el trabajador en la solicitud (art. 11. 1 PLA 1998).Tal escrito debe contener una declaración en forma de resumen sobre los motivos de la postergación (art. 11. 3 PLA 1998).

Como regla general, la ley sólo permite aplazamiento, a menos que la causa de postergación sea la variación estacional en el volumen de trabajo, en cuyo caso, la concreta licencia puede ser pospuesta no más de dos veces (art. 11. 4 PLA 1998).

Si por el hecho de retrasar la licencia parental debido a causas de funcionamiento empresarial, el periodo llega a su fin en virtud de operar los límites legales (edad del hijo o cese de discapacidad o enfermedad), la licencia parental aplazada dará lugar a un derecho diferido, es decir, más allá de la fecha normal de caducidad (art. 11.6 PLA 1998). Cuando el aplazamiento incide en un permiso parental fraccionado, salvo acuerdo entre contra, debe aplicarse a los dos periodos fraccionados [art. 11.6 A) PLA 1998].

El empleador también está obligado a seguir el procedimiento anterior y proporcionar una razón justificadas para rechazar una solicitud de permiso parental flexible (art. 11.8 PLA 1998).

\section{- Denegación:}

El legislador recoge expresamente la potestad empresarial para denegar la solicitud de ejercer el permiso parental cuando existan motivos razonables (en todo caso, justificados, art. 12.5 PLA 1998) para creer que el trabajador no tiene derecho (art. 12. 4 PLA 1998).

Cuando lo solicitado es un permiso de cuidador, el único motivo a esgrimir por el empresario para oponerse al derecho es cuando la duración solicitada sea inferior a 13 semanas y además existan razones justificadas de las que tiene que dar cuenta por escrito (art. 8.2 CLA 2001). 


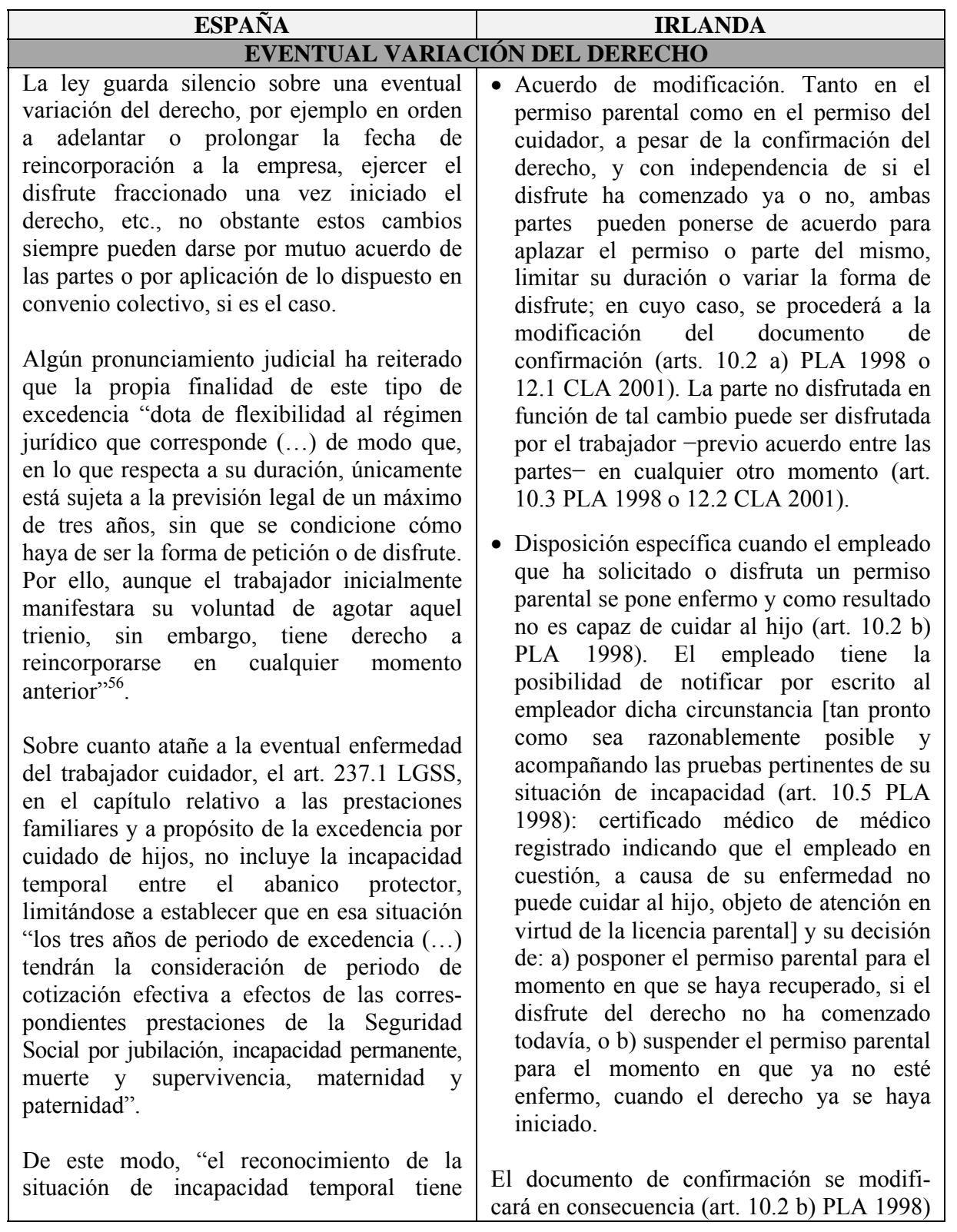

56 STSJ Cataluña 13 julio 2004 (Sentencia 5405). En el mismo sentido, aunque el punto de discrepancia verse sobre la posibilidad de prolongar e derecho hasta el máximo legal sin necesidad de solicitar ulteriores prórrogas, y alegando que "sería muy discutible admitir que el trabajador puede renunciar «a priori» al ejercicio de un derecho de esta naturaleza, limitando ya la duración de la excedencia en el momento mismo de solicitarla o serle concedida, cuando desconoce las necesidades y exigencias de futuro que le puede originar el cuidado del hijo", STSJ Cataluña 19 noviembre 1999 (Rec. 6228). 


\begin{tabular}{|l|l|}
\hline $\begin{array}{l}\text { como presupuesto hallarse en servicio } \\
\text { activo"57 y no en situación de excedencia }^{58} .\end{array}$ & $\begin{array}{l}\text { y, durante ese tiempo, el trabajador será } \\
\text { tratado como un empleado enfermo. }\end{array}$ \\
& $\begin{array}{l}\text { Si por el hecho de postergar o suspender la } \\
\text { licencia parental por causa de enfermedad, } \\
\text { el periodo llega a su fin en virtud de operar } \\
\text { los límites legales (edad del hijo o cese de } \\
\text { discapacidad o enfermedad), la licencia } \\
\text { parental pospuesta o suspendida dará lugar } \\
\text { a un derecho diferido, es decir, más allá de } \\
\text { la fecha normal de caducidad (art. 10.4 } \\
\text { PLA 1998). }\end{array}$ \\
\hline
\end{tabular}

\begin{tabular}{|c|c|}
\hline ESPAÑA & IRLANDA \\
\hline \multicolumn{2}{|c|}{ SIMULTANEIDAD CUIDADORES } \\
\hline $\begin{array}{l}\text { El legislador español dispone que si dos o } \\
\text { más trabajadores de la misma empresa } \\
\text { generasen el derecho a la excedencia para } \\
\text { cuidar al mismo sujeto causante, el } \\
\text { empresario podrá limitar su ejercicio } \\
\text { simultáneo por razones justificadas de } \\
\text { funcionamiento de la empresa (art. } 46.3 \\
\text { ET). Esta limitación parece no implicar } \\
\text { una prohibición total a la simultaneidad, } \\
\text { únicamente restringe la posibilidad de } \\
\text { ejercitar el derecho conciliatorio de forma } \\
\text { simultanea cuando dos trabajadores } \\
\text { prestan servicios en la misma empresa y } \\
\text { sólo si el empleador lo estima oportuno } \\
\text { por razones justificadas, por lo que la } \\
\text { simultaneidad será factible cuando los } \\
\text { titulares del derecho desarrollen la } \\
\text { actividad en empresas distintas o cuando, a } \\
\text { pesar de ser compañeros de trabajo, el } \\
\text { empresario no hace uso de la limitación } \\
\text { conferida. }\end{array}$ & $\begin{array}{l}\text { La ley que regula el permiso parental en } \\
\text { Irlanda guarda silencio sobre la } \\
\text { coincidencia de cuidadores por un mismo } \\
\text { sujeto causante, sin embargo, cuando el } \\
\text { derecho conciliatorio se ejerce para el } \\
\text { cuidado genérico de personas, el legislador } \\
\text { prevé expresamente la imposibilidad del } \\
\text { empleado de acogerse al permiso "durante } \\
\text { el mismo periodo en el cual otro empleado } \\
\text { está proporcionando la atención a esa } \\
\text { misma persona" (art. 6.3 CLA 2001). }\end{array}$ \\
\hline
\end{tabular}

57 Sobre la denegación de la solicitud de suspensión de la excedencia por cuidado de hijo y reconocimiento de baja laboral por intervención quirúrgica, STS (Contenciosoadministrativo) 2 noviembre 2015 (Rec. 169).

58 Cuestión distinta sería la situación de aquella trabajadora que, estando de baja laboral, solicita excedencia por cuidado de hijo para una fecha posterior en la que suponía habría causado alta por curación pero no fuera así, STSJ Galicia 30 junio 2008 (Rec. 4343/2005). 


\begin{tabular}{|c|c|}
\hline ESPAÑA & IRLANDA \\
\hline \multicolumn{2}{|c|}{ TRANSFERENCIA DEL DISFRUTE } \\
\hline $\begin{array}{l}\text { La regla general viene dada por la } \\
\text { imposibilidad de transferir la excedencia por } \\
\text { motivos familiares, sobre todo si tenemos en } \\
\text { cuenta que el reconocimiento individualizado } \\
\text { (propio y no derivado) significa que "no se } \\
\text { puede optar por ceder el derecho. Si no se } \\
\text { disfruta (...), se pierde"59 pues, en todo caso, } \\
\text { el periodo de excedencia que uno de los } \\
\text { trabajadores tiene reconocido y no ejercita no } \\
\text { supone la acumulación al tiempo de } \\
\text { conciliación del otro empleado. } \\
\text { Esto "es consustancial a la propia finalidad } \\
\text { de la norma, que no se limita a dar una } \\
\text { respuesta legal a la necesidad de cuidado que } \\
\text { los familiares más próximos pueden requerir, } \\
\text { sino que aspira a promover el reparto de las } \\
\text { cargas familiares"60. } \\
\text { No obstante, la transferencia tiene una } \\
\text { estrecha relación con la limitación sobre la } \\
\text { acumulación de cuidadores por un mismo } \\
\text { sujeto causante (y no sólo la establecida en la } \\
\text { ley a disposición del empleador sino también } \\
\text { la decidida por los propios empleados a } \\
\text { consecuencia de que, además de producirse } \\
\text { un exceso de cuidadores -y un posible abuso } \\
\text { de derecho-, en la mayoría de los casos será } \\
\text { difícil poder permitirse ambos trabajadores } \\
\text { abandonar temporalmente el empleo para } \\
\text { cuidar a su familia y sobre todo dejar con ello } \\
\text { de percibir remuneración); en consecuencia se } \\
\text { entiende que cabe la transferencia indirecta } \\
\text { (entre progenitores, entre un padre y un } \\
\text { abuelo, o entre parientes, etc.), de considerar } \\
\text { que unos titulares pueden renunciar (antes } \\
\text { que ceder) a su derecho conciliatorio en } \\
\text { beneficio de otros. }\end{array}$ & $\begin{array}{l}\text { Aunque la experiencia internacional ha } \\
\text { demostrado que, cuando se le permite la } \\
\text { transferencia de la licencia parental, el tráfico } \\
\text { es invariablemente en una dirección: de } \\
\text { padres a madres, en la normativa irlandesa } \\
\text { cabe una excepción a la regla general de } \\
\text { imposibilidad de transferir el permiso } \\
\text { parental, ya de forma total o parcial, a } \\
\text { cualquier otro progenitor. } \\
\text { Se permite la transferencia si ambos progeni- } \\
\text { tores trabajan en la misma empresa y exista } \\
\text { el consentimiento del correspondiente } \\
\text { empleador. En todo caso, únicamente cabe } \\
\text { ceder } 14 \text { de las } 18 \text { semanas, es decir, por lo } \\
\text { menos cuatro son intransferibles (art. } 6.6 \\
\text { PLA). }\end{array}$ \\
\hline
\end{tabular}

59 PÉREZ DEL RIO, T.: "El principio de igualdad de trato y la prohibición por razón de sexo en el Derecho Comunitario", en AA.VV.: Mujer y Trabajo, Albacete (Bomarzo), 2003, pág. 310.

60 SÁNCHEZ-RODAS NAVARRO, C.: La excedencia por cuidados de familiares. El régimen jurídico de los cuidadores no profesionales, Valencia (Tirant lo Blanch), 2008, pág. 27. 


\begin{tabular}{|c|c|}
\hline ESPAÑA & IRLANDA \\
\hline \multicolumn{2}{|c|}{ ADVENIMIENTO DE UN NUEVO DERECHO } \\
\hline $\begin{array}{l}\text { El legislador apunta que cuando otro sujeto } \\
\text { causante hiciera surgir el derecho a un nuevo } \\
\text { período de excedencia, el inicio del mismo } \\
\text { pondrá fin al que, en su caso, se viniera } \\
\text { disfrutando (art. } 46.3 \mathrm{ET} \text { ). } \\
\text { Contrariamente a lo que establece el legisla- } \\
\text { dor con respecto a la excedencia voluntaria } \\
\text { ordinaria, en cuanto a la imposibilidad de } \\
\text { ejercer el derecho otra vez si han transcurrido } \\
\text { cuatro años desde el final de la anterior } \\
\text { excedencia (art. } 46.2 \text { ET), en esta especial } \\
\text { excedencia no se establece límite alguno }\end{array}$ & $\begin{array}{l}\text { El trabajador tiene derecho a un permiso } \\
\text { parental respecto de cada hijo (art. } 6.4 \text { PLA } \\
\text { 1998). Si tuviera más de un descendiente (y } \\
\text { no se trata de un parto múltiple), aun cuando } \\
\text { ostenta el derecho a un permiso parental de } \\
18 \text { semanas por cada uno, el periodo de } \\
\text { disfrute no podrá ser superior a } 18 \text { semanas en } \\
\text { un periodo de } 12 \text { meses, salvo que medie } \\
\text { consentimiento empresarial (art. } 7.3 \text { PLA } \\
\text { 1998). La excepción se sitúa en casos de parto } \\
\text { múltiple. } \\
\text { En el permiso del cuidador existen requisitos } \\
\text { adicionales, según el caso: } \\
\text { - Si se está ejerciendo un derecho de la } \\
\text { misma naturaleza: El permite al trabajador } \\
\text { puede solicitar otra licencia (que seguirá el } \\
\text { mismo procedimiento formal que la } \\
\text { anterior) para cuidar a otra persona } \\
\text { siempre y cuando esta última resida con la } \\
\text { persona relevante primera (art. } 7.2 \text { CLA } \\
\text { 2001), es decir, para atender a dos } \\
\text { personas que viven juntas y ambas tienen } \\
\text { la necesidad atención a tiempo completo. } \\
\text { En esta situación, ninguno de los periodos } \\
\text { de permiso de cuidador podrá exceder de } \\
\text { 104 semanas desde su comienzo (marcado } \\
\text { en la decisión del Ministro) y, consecuen- } \\
\text { temente, la duración total de ambos } \\
\text { derechos no podrá ser superior a 208 } \\
\text { semanas (art. 7.4 CLA 2001). } \\
\text { Como límite máximo, la ley prevé la } \\
\text { imposibilidad del empleado, que ejerza este } \\
\text { permiso con respecto a dos personas } \\
\text { relevantes, de solicitar otro para prestar } \\
\text { atención a una tercera persona (art. } 7.5 \text { CLA } \\
\text { 2001): } \\
\text { - Si el permiso del cuidador ya ha termi- } \\
\text { nado: el trabajador no tiene derecho a } \\
\text { iniciar un nuevo periodo de permiso en } \\
\text { relación con otra persona relevante hasta } \\
\text { desde la finalización del permiso anterior. }\end{array}$ \\
\hline
\end{tabular}


ESPAÑA $\quad$ IRLANDA

TERMINACIÓN DEL DERECHO

El permiso del cuidador termina por lo general en la fecha especificada en el documento de confirmación [art. 11.1 a) CLA 2001], no obstante también puede concluir por acuerdo entre empresario y trabajador [art. 11.1 b) CLA 2001] y por otras razones de las que cabe dar cuenta:

- Cuando la persona que está siendo atendida deja de cumplir los requisitos de persona relevante [art. $11.1 \mathrm{c}$ ) CLA 2001].

- Cuando el empleado no cumple las condiciones de proporcionar la "atención y cuidado a tiempo completo" exigido [art. 11.1 d) CLA 2001].

- Cuando la persona relevante fallece [art. 11.1 f) CLA 2001], en cuyo caso, el permiso terminará a las 6 semanas siguientes de la muerte o en la fecha especificada en el documento de confirmación si fuera anterior.

- Por decisión oficial del Ministro de Protección Social (art. 11.2 CLA 2001), notificada al empresario y al trabajador tan pronto como sea posible (art. 11.2 in fine CLA 2001) basada en alguno de los siguientes supuestos:

- No cumplir los requisitos de persona relevante [art. 11.2 a) CLA 2001].

- No brindar los requisitos de atención y cuidado a tiempo completo [art. 11.2 b) CLA 2001].

- El trabajador está desarrollando o ha ocupado durante el permiso del cuidador un empleo o autoempleo prescrito [art. 11.2 c) CLA 2001], es decir, cuando la actividad por cuenta ajena o propia sobrepasa las 15 horas por semana

Recibida por el empresario, la decisión oficial de terminación del permiso del cuidador, debe notificar al trabajador, tan pronto como sea posible, la fecha concreta (y razonable) en que debe reingresar al trabajo (art. 11.3 CLA 2001). El trabajador debe reincorporarse a la empresa en la fecha especificada sabiendo que el tiempo que reste entre esta fecha y la que se acordó en el documento de confirmación no será considerado como permiso conciliatorio (art. 11.4 CLA 2001). Efectuada la reincorporación, el empresario debe notificar este hecho al Ministro de Protección Social (art. 11.5 CLA 2001).

La ley también recoge en el art. 11.7 CLA 2001 la manera de notificación al trabajador, previendo tanto la entrega personal como la remisión postal certificada a la dirección que consta como la última residencia del empleado o, cuando corresponda, a la residencia de la persona relevante. 


\begin{tabular}{|c|}
\hline ESPAÑA \\
\hline DERECHOS Y CONDICIONES LABORAR \\
\hline - Derecho a la reserva de su puesto de trabajo \\
durante el primer año (el cómputo se cuenta a \\
partir del inicio del periodo de excedencia y no \\
desde el nacimiento u orden de adopción, \\
acogimiento...) y de un puesto del mismo \\
grupo profesional o categoría equivalente \\
durante el segundo y tercer año. En caso de \\
familia numerosa, la reserva del mismo puesto \\
se amplía durante máximo 15 (familia \\
numerosa general) o 18 meses (familia \\
numerosa especial). \\
- Periodo computable a efectos de antigüedad. \\
- Asistencia cursos de formación (derecho a ser \\
convocado por el empresario, en especial con \\
ocasión de su reincorporación) \\
- Periodo de cotización efectiva a efectos de \\
prestaciones de Seguridad Social (jubilación, \\
IP, muerte y supervivencia, maternidad y \\
paternidad) y situación asimilada al alta: \\
cuidado de hijos (3 años) y cuidado de \\
familiares (1 año).
\end{tabular}

En España, la situación de excedencia por motivos familiares, no interrumpen el cómputo del periodo de prueba (art. 14.3. $1^{\circ}$ ET) o el periodo de contrato de trabajo en prácticas (art. 11.1 b) $2^{\circ}$ ET) o para la formación y el aprendizaje (art. 11.2 b) $3^{\circ}$ ET) aunque siempre cabe acuerdo con el empleador o previsión en convenio colectivo.

Los obligación de respetar los derechos adquiridos o en proceso de adquisición por los trabajadores que disfrutan de un permiso parental "debe interpretarse en el sentido de que expresa un principio de Derecho social comunitario que reviste una especial importancia y que, por tanto, no puede ser interpretado de manera restrictiva" ${ }^{\prime 61}$, sin embargo, la Directiva no impone obligaciones a los Estados Miembros para garantizar que los empleados continúan recibiendo los beneficios de la Seguridad Social durante el permiso parental ${ }^{62}$.
IRLANDA

ILES Y DE SEGURIDAD SOCIAL

El tiempo dedica al cuidado de hijos o personas en virtud de estos permisos se considera a todos los efectos como si no hubiera estado ausente en el empleo, por lo que ninguno de sus derechos laborales pueden verse afectados (art. 14. 1 PLA 1998 ${ }^{63}$ y art. 13.1 CLA 2001) excepto:

- En el permiso parental: el correspondiente a la remuneración y a los beneficios de jubilación o cualquier otra obligación de cotizar.

- En el permiso del cuidador: el relativo a la remuneración, las vacaciones y días festivos (sólo genera el derecho con respecto a las primeras 13 semanas de permiso de cuidador, art. 13.2 y art.3 CLA 2001), a los beneficios de jubilación y a cualquier otra obligación de cotizar.

Los periodos del permiso parental o de cuidado de personas no se consideran como parte de otro permiso de empleo, incluyendo las licencias por enfermedad, vacaciones anuales, adopción, maternidad y fuerza mayor (art. 14. 2 PLA 1998 y art. 13.4 CLA 2001).

Si el trabajador que inicia el permiso parental o el permiso del cuidador se encuentra en período de prueba o está contratado en virtud de un contrato en formación o en aprendizaje, el empresario puede acordar que el cómputo de tales situaciones se interrumpan durante el derecho conciliatorio (art. 14. 3 PLA $1998 \mathrm{y}$ art. 13.5 CLA 2001).

A la terminación del permiso parental o permiso del cuidador, independientemente cuáles fueran las causas, el empleado tiene derecho a regresar al trabajo realizado inmediatamente antes de iniciar el permiso (generalmente, el mismo puesto de trabajo, salvo que no hubiera estado desarrollando con

61 STJUE 116/08, de 22 octubre 2009, asunto Meerts $v$ Proost NV.

62 "La determinación de la medida en que el trabajador puede seguir adquiriendo derechos de Seguridad Social mientras disfruta de un permiso parental a tiempo parcial es tarea de los Estados miembros", STJUE 537/07, de 16 julio 2009, asunto Gómez-Limón SánchezCamacho.

63 En este contexto, es de especial interés la STJCE 333-97, de 21 octubre 1999, asunto Lewen $v$ Denda. El Tribunal de Justicia declaró que el artículo 119 del Tratado CE se 
Ante este hecho, o por ejemplo ante la imposibilidad de la prestación por una eventual interrupción del trabajo en la empresa, resultaría operativo el art. 30 ET en virtud del cual "Si el trabajador no pudiera prestar su servicios una vez vigente el contrato porque el empresario se retrasare en darle trabajo por impedimentos imputables al mismo y no al trabajador, este conservará el derecho a su salario, sin que pueda hacérsele compensar el que perdió con otro trabajo realizado en otro tiempo".

Cabe contemplar la posibilidad de suscribir un convenio especial con la Seguridad Social como cuidador no profesional al amparo del RD 615/2007, de 11 de mayo "por los períodos en que el cuidador no profesional esté disfrutando de los periodos de excedencia laboral en razón de cuidado de familiares, que tengan la consideración de periodos de anterioridad su trabajo normal o habitual, hecho que también apunta el legislador en el art. 15. 2 PLA 1998 y art. 14.2 CLA 2001), en el marco del mismo contrato de trabajo y bajo idénticos términos y condiciones de empleo. En consecuencia, la incorporación no ha de tener lugar en condiciones menos favorables a las precedentes; antes al contrario, habrá de incluir cualquier mejora en la remuneración $\mathrm{u}$ otros aspectos laborales acaecidos mientras estaba en ejerciendo el derecho conciliatorio [art. 15.1 PLA 1998 y art.14.1 c) CLA 2001].

Si no es razonable o factible el regreso al mismo puesto, el empresario debe ofrecer al trabajador una alternativa de empleo adecuada (art. 16.1 PLA y art. 15.1 CLA 2001). En cuanto hace al término 'adecuado', ${ }^{\text {, }}$, el legislador ofrece unas

opone a que un empleador excluya por completo a las trabajadoras femeninas que disfrutan de un permiso parental del pago de una gratificación de carácter voluntario de Navidad, sin tener en cuenta el trabajo realizado en el año en que se concede la gratificación, ni tampoco el período de descanso por maternidad durante el cual se le prohibió trabajar, cuando esa gratificación tiene la finalidad de retribuir retroactivamente el trabajo realizado durante ese año (la justificación alegada por el empleador radicaba en hacer de la gratificación un aliciente para el trabajo futuro, algo que no puede esperar, a corto plazo, de una mujer que disfruta de un permiso parental durante cierto tiempo). El Tribunal declaró que un trabajador que ejerce el derecho legal a disfrutar de un permiso parental (y que conlleva el pago de una prestación de crianza por parte del Estado alemán) se encuentra en una situación específica, que no puede asimilarse con la de un hombre o una mujer que trabajen, puesto que dicho permiso implica la suspensión del contrato de trabajo y, por lo tanto, de las respectivas obligaciones del empleador y el trabajador.

Por lo tanto, el Derecho comunitario no es contrario a la negativa a pagar dicha gratificación a una mujer que disfruta de un permiso parental cuando la concesión de la mencionada gratificación está sujeta a la única condición de que el trabajador se encuentre en activo en el momento de su concesión, pero el artículo 119 del Tratado CE se opone a que un empleador, al conceder una gratificación de Navidad, tenga en cuenta, con el objeto de reducir proporcionalmente la prestación, los periodos de descanso de maternidad y durante los cuales se prohíbe trabajar. Sin embargo, el Derecho comunitario es acorde a la decisión de un empleador en virtud de la cual, al conceder una gratificación de Navidad a una trabajadora que está en permiso parental, tenga en cuenta los períodos de permiso parental, a fin de reducir proporcionalmente la prestación. Part. 8A, 80 G, 1. b) Employment Rights Act 1996, http://www.legislation.gov.uk/ukpga/1996/18/section/80G.

En palabras de los Tribunales, requiere "un análisis subjetivo de la labor realizada y las condiciones de empleo del empleado antes de tomar la licencia" e incluso con respecto de sus concretas circunstancias, EAT Tighe $v$ Travenol Laboratories (Ltd P14/1986), al respecto de la reclamación de un una mujer alegando que había sido "constructiva" e injustamente despedida, pues cuando terminó la licencia de maternidad regresó a un trabajo de producción, cuando en el tiempo inmediatamente anterior prestaba servicios como empleada de oficina. El Tribunal tomó en consideración la prueba subjetiva y afirmó que la naturaleza del trabajo involucrado en la producción es muy diferente del 
cotización efectiva, de acuerdo con lo previsto en el artículo 180 [actual 237] Ley General de la Seguridad Social" (art. 2.3 RD). nociones básicas: se trata de un empleo apropiado para el trabajador en cuestión atendiendo a sus circunstancias, y en términos no menos favorables en comparación con el anterior trabajo (incluyendo las mejoras). Además, procederá considerar el lugar donde debe desarrollarse la prestación, la capacidad del empleado y ponderar si media la continuidad en el servicio (art. 16.2 PLA y art. 15.2 CLA 2001).

La norma se preocupa de un adecuado retorno del trabajador cuando se ha producido un cambio de empresario, refiriéndose al empleador "sucesor" [art. 15.1 a) PLA 1998 o art. 14.1 a) CLA 2001]. De manera diferente, igual ocurre cuando el trabajador reincorporarse debido a una interrupción o cese del trabajo en la empresa, supuesto ante el cual el trabajador tendría que esperar y regresar a trabajar cuando se reanude la actividad en la empresa o tan pronto como sea posible después de tal reanudación (art. 15.3 PLA 1998 y art. 14.3 CLA 2001).

\begin{tabular}{|l|l|}
\hline ESPAÑA & \multicolumn{1}{|c|}{ IRLANDA } \\
\hline \multicolumn{2}{|c|}{ REINGRESO AL TRABAJO } \\
\hline & $\begin{array}{l}\text { La única mención legal sobre el reingreso } \\
\text { al trabajo aparece respecto al permiso del } \\
\text { cuidador, requiriendo al empleado, que } \\
\text { tenga la intención de reincorporarse a la } \\
\text { empresa, preavisar a su empleador con una } \\
\text { antelación de 4 semanas a la fecha de } \\
\text { reingreso (art. 9.6 CLA 2001), exigencia } \\
\text { exenta de cumplir si el derecho termina por } \\
\text { decisión oficial (art. 9.7 CLA 2001). }\end{array}$ \\
\hline
\end{tabular}

trabajo de oficina, no considerando apropiado desde el punto de vista del empleado, aunque la dirección argumentara que el trabajo de producción era apropiado para el empleado dadas las circunstancias, LAW SOCIETY OF IRELAND (MOFFATT, J., Ed.): Employment Law, cit., pág. 132. 


\section{ESPAÑA \\ DERECHO A SOLICITAR CAMBIOS EN EL TRABAJO}

En cualquier momento, y no sólo cuando el trabajador se reincorpora a la empresa después de haber disfrutado de una excedencia por motivos familiares, es posible solicitar una reducción de jornada por guarda legal (art. 37.5 ET) o una adaptación de la jornada de trabajo para conciliar (art. 34.8 ET).

Estos beneficios vienen referidos únicamente al horario (no al trabajo funcional) y presentan las siguientes características:

La reducción de jornada diaria por guarda legal (art. $37.5 \mathrm{ET}$ ) con la disminución proporcional del salario, opera entre:

- Al menos, un octavo y un máximo de la mitad de la duración de aquélla. Para cuidado directo de: 1) menor de 12 años o persona con discapacidad física, psíquica o sensorial, que no desempeñe una actividad retribuida o 2) Familiar, hasta el $2^{\circ}$ grado de consanguinidad o afinidad, que por razones de edad, accidente o enfermedad no pueda valerse por sí mismo, y que no desempeñe actividad retribuida.

- Al menos, la mitad de la duración de aquélla, para el cuidado durante la hospitalización y tratamiento continuado, del menor a su cargo afectado por cáncer (tumores malignos, melanomas y carcinomas), o por cualquier otra enfermedad grave que implique un ingreso hospitalario de larga duración y requiera la necesidad de su cuidado directo, continuo y permanente, acreditado por el informe del Servicio Público de Salud u órgano administrativo sanitario de la Comunidad Autónoma correspondiente y, como máximo, hasta que el menor cumpla los 18 años. Por convenio

El empleado que retorna al trabajo después un permiso parental, tiene derecho a solicitar un cambio en las horas o en el patrón de trabajo (o en ambos), por un periodo determinado (art. 15.A PLA).

La solicitud se debe presentar por escrito tan pronto como sea razonablemente posible, pero no más allá de las seis semanas anteriores a la fecha de comienzo de la propuesta en cuestión, especificando la naturaleza de los cambios solicitados y la fecha de inicio y la duración del período de la misma (art. 15.A. 2 PLA).

El empresario debe considerar tal petición teniendo en cuenta tanto sus propias necesidades como las del empleado, pero no está obligado a concederla (art. 15.A. 3 PLA) ${ }^{65}$. Su respuesta, concediendo o no lo instado, debe notificarse por escrito tan pronto como sea razonablemente factible, pero a más tardar dentro de las cuatro semanas después de la recepción de la solicitud del empleado (art. 15.A. 3 PLA).

Si se acepta la solicitud, sobre el empleador pesa la obligación de preparar un acuerdo donde aparezcan la naturaleza de los cambios, la fecha de inicio y la duración del período, que puede ser decidido entre ambas partes (art. 15.A. 3 PLA).

El empresario debe conservar el acuerdo (firmado por el trabajador afectado) y entregar una copia al interesado, quien también tiene el deber de conservarla (art. 15.A. 5 PLA 1998).

65 En Reino Unido, estas solicitudes sólo pueden ser rechazadas por "razones empresariales", tales como: asunción de costes adicionales; efecto perjudicial sobre la capacidad para satisfacer la demanda del cliente; incapacidad para reorganizar el trabajo entre el personal existente; incapacidad para contratar personal adicional; repercusión perjudicial en la calidad; impacto negativo en el rendimiento; insuficiencia de trabajo durante los períodos que el empleado se propone trabajar o cambios estructurales planeados. Además, si el empleador desea rechazar la solicitud, el empleado debe ser invitado a una reunión para discutir la situación dentro de los 28 días siguientes a la fecha en que el empleador recibe la solicitud, en SMITH, I. Y BAKER, A.: Smith \& Wood's Employment Law, 11 ${ }^{\text {a }}$ ed., Oxford (Oxford University Press), 2013, pág. 288. 


\begin{abstract}
colectivo, cabrá establecer las condiciones y supuestos en los que esta reducción de jornada se podrá acumular en jornadas completas.
\end{abstract}

La concreción horaria y la determinación del período de disfrute de la reducción de jornada corresponden al trabajador ${ }^{66}$, dentro de su jornada ordinaria. No obstante, los convenios colectivos podrán establecer criterios en atención a los derechos de conciliación de la vida personal, familiar y laboral del trabajador $\mathrm{y}$ las necesidades productivas y organizativas de las empresas $^{67}$.

El trabajador, salvo fuerza mayor, deberá preavisar al empresario con una antelación de quince días o la que se determine en el convenio colectivo aplicable, precisando la fecha en que iniciará y finalizará el permiso de lactancia o la reducción de jornada.

La adaptación de la jornada de trabajo para conciliar (art. 34.8 ET) se hace en los términos que se establezcan en la negociación colectiva o en acuerdo entre empresario y trabajador.
El trabajador puede revocar esta solicitud siempre que lo comunique por escrito al empresario antes de que el concreto acuerdo esté formalizado (art. 15.A. 6 PLA 1998).

66 "Ello supone que, en los supuestos de colisión de interés entre el trabajador y el empresario, debe prevalecer aquella posición que pueda considerarse más idónea para la atención del menor. Ahora bien el ejercicio del derecho debe estar regido por los principios de buena fe y no resultar en extremo perjudicial para el empresario; por tanto la concreción horaria en materia de reducción de jornada para el cuidado de un menor siendo un derecho básico del trabajador, no puede considerarse un derecho absoluto que prevalezca cualquiera que sean las consecuencias que ello provoque en el empresario", STSJ La Rioja 10 febrero 2012 (Rec. 22).

67 El juez avaló la decisión de la empresa que negó la concreción horaria a disfrutar por la trabajadora en la reducción de jornada por guarda legal amparándose en aplicación del convenio colectivo que no permitía la reducción de la jornada de la forma y modo solicitada (en días sueltos), sino que lo debía hacer en bloque, STSJ Cataluña 3 junio 2013 (Rec. 6219/2012). 


\section{ESPAÑA}

\section{GARANTÍA DE INDEMNIDAD}

La finalidad tuitiva que la excedencia por motivos familiares trata de materializar en favor del trabajador perdería fuerza si no contara con el amparo derivado del hecho de proteger a quien acuda a este derecho conciliatorio frente a la extinción del vínculo contractual, en particular, mediante el despido. Así, el legislador español, en línea con la Cláusula 5.2 de la Directiva 2010/18/UE, del Consejo, de 8 de marzo de 2010, reconoce específicamente como nulos (con la consecuencia de la readmisión inmediata del trabajador/a y el abono de los salarios dejados de percibir) aquellos despidos, ya sean por causas objetivas por causas objetivas (art. 53.4 b) ET) o por razones disciplinarias (art. $55.5 \mathrm{~b}$ ) ET) a aquellos trabajadores que hayan solicitado o estén disfrutando la excedencia prevista en el art. 46.3 ET.

La diferencia con el sistema irlandés es patente pues en España no protege expresamente frente a cualquier represalia posible, pues tas no tienen que venir necesaria y exclusivamente referidas con el despido objetivo o el disciplinario, sino que pueden adoptar la forma de una decisión de movilidad funcional o geográfica o una modificación de condiciones de trabajo, etc. En este caso, la protección debería solicitarse a través del procedimiento de tutela antidiscriminatoria con los problemas de demostración de indicios que supone a efectos de inversión de la carga de la prueba.

Además, hay quien en la doctrina $^{68}$ ha apreciado alguna carencia más en la normativa española, de un lado, que la especial protección "referente a la calificación de la nulidad del despido no hace referencia al despido causalizado por el disfrute de los permisos establecidos en el art. 37.3 ET, mientras sí que se hace referencia expresa a los contemplados en $\operatorname{los} \mathrm{n}^{\mathrm{o}} 4$ y 5 del mismo precepto. No se garantiza frente a las represalias adoptadas por quien emplea en caso de ejercicio incontenido
La legislación protege a los progenitores que están disfrutando $\mathrm{o}$ han disfrutado de un permiso parental o permiso del cuidador [e igualmente cuando se ejerza o se haya ejercido el derecho a solicitar el cambio en las horas de trabajo o en el patrón de trabajo en virtud del art. 15 a) PLA 1998], prohibiendo al empleador penalizarlo por ejercer el derecho conciliatorio en los siguientes ámbitos: despido, trato injusto --incluyendo la selección para los despidos--, o un cambio desfavorable en las condiciones laborales (art. 16.A. 1 y 2 PLA 1998 y art. 16.1 y 2 CLA 2001). A menos que, teniendo en cuenta todas las circunstancias, hubiera razones de peso que justificaran la decisión empresarial, el despido será tachado de improcedente (art. 16.A. 3 y 4 PLA 1998 y art. 16. 3 y 4 CLA 2001), entendiéndose realizado en la fecha en que tenía derecho a volver al trabajo por finalizar el permiso. En virtud del art. 7.1 Unfair Dismissals Act, 1977 to 2007 (No. 10) ${ }^{69}$ o Ley de despidos injustos, el órgano judicial concederá al trabajador uno de los siguientes recursos: reincorporación al trabajo en los términos ante expuestos, compromiso de una nueva contratación o compensación de hasta un máximo de 2 años de salario).

68 PÉREZ DEL RIO, T.: "El principio de igualdad de trato y la prohibición por razón de sexo en el Derecho Comunitario", cit. pág. 310.

69 http://www.lawreform.ie/_fileupload/RevisedActs/WithAnnotations/HTML/EN_ACT_ 1977_0010.htm. 
de los derechos (como ocurre por ejemplo en el supuesto contemplado por el art. 21.4 de la LPRL) de tal manera que ante una negativa empresarial, el trabajador y la trabajadora deben obedecer y después reclamar judicialmente.

\section{BIBLIOGRAFÍA}

AGRA VIFORCOS, B.: "Principales Líneas programáticas y normativas diseñadas en la Comunidad Autónoma de Castilla y León para la tutela de las situaciones de monoparentalidad", Revista de Investigación Económica y Social de Castilla y León, núm. 11, 2008.

- "Algunos interrogantes sobre las familias numerosas", Conferencia en el Primer Foro Nacional de Familias Monoparentales, 2010.

- "Dificultades para la integración laboral de las familias monoparentales", en AA.VV. (RODRÍGUEZ ESCANCIANO, S. y MARTÍNEZ BARROSO, M. R., Dirs. y ÁLVAREZ CUESTA, H., Coord.): La inserción de las mujeres en riesgo de exclusión social, Valencia (Tirant lo Blanch), 2015.

CORTE HEREDERO, N.: "La atención de las responsabilidades familiares a través de la excedencia laboral: examen del artículo 46.3 del Estatuto de los Trabajadores", Documentación Laboral, núm. 59, 1999.

DALY, M., y CLAVERO, S.: Contemporary family police in Ireland and Europe, Dublin (Department of Social and Family Affairs), 2002.

- Contemporary Family Policy: A Comparative Review of Ireland, France, Germany, Sweden and the UK, Dublin (Institute of Public Administration), 2002.

DAVID, R. y JAUFFRET-SPINOSI, C.: Los grandes sistemas jurídicos contemporáneos, $11^{\mathrm{a}}$ ed., México (Universidad Nacional), 2010.

DEPARMENT OF EDUCATION AND SCIENCE PRIMARY BRANCH: Carer's Leave for Primary Teachers, 2003.

DEPARTAMENT OF EDUCATION AND SCIENCE: Carer's Leave for Teachers in Second Level Schools, 2003.

DEPARTAMENT OF EDUCATION AND SKILLS: Parental Leave- Amendment for Staff in Institutes of Technology, 2012.

- Parental Leave entitlements for registered teachers in recognised Primary and Post Primary Schools (Circular 0026/2013), 2013.

DEPARTAMENT OF JOBS, ENTERPRISE AND INNOVATION: Carer's Leave Act, 2001. Explanatory Booklet for Employers and Employees, Dublin, 2011.

DEPARTAMENT OF PUBLIC EXPENDITURE AND REFORM: Parental Leave in the Civil Service, 2013. 
- Circular 13/2010: Amendment to Parental Leave Arrangements (age), 2010.

DUBLIN INSTITUTE OF TECHNOLOGY: Parental leave policy \& guidelines, 2015.

EUROFOUND: Promoting uptake of parental and paternity leave among fathers in the European Union, Luxemburgo (Oficina de publicaciones de la Unión Europea), 2015.

FAULKNER, M.: Essentials of Irish Labour Law, $2^{\mathrm{a}}$ ed., Dublin (Gill \& Macmillan), 2013.

FERNÁNDEZ-COSTALES MUÑIZ, J.: "Salud y mujer en la negociación colectiva", en AA.VV. (RODRÍGUEZ ESCANCIANO, S.; MARTÍNEZ BARROSO, M.R. y ÁLVAREZ CUESTA, H., Dirs.): La igualdad por razón de género en los procesos de negociación colectiva: análisis de la situación actual y propuesta de futuro, Pamplona (Aranzadi), 2016.

GOVEMMENT OF IRELAND, PROGRAMME FOR PROSPERITY AND FAIRNESS: Report of the working group review of the Parental Leave Act 1998, Dublin, Stationery Office, 2002.

HEPPLE, B.: "The contribution of comparative law to understanding labour relations", en AA.VV. (GORELLI HERNÁNDEZ, J., Dir.): El derecho a la negociación colectiva: "Liber Amicorum" Profesor Antonio Ojeda Avilés, Sevilla (Consejo Andaluz de Relaciones Laborales), 2014.

IRISH GOVERNMENT: Legislation Programme Spring/Summer Session 2015, enero 2015.

KAHN-FREUND, O.: "On uses and misuses of comparative law", The Modern Law Review, Vol. 37, núm. 1, 1974.

LAW SOCIETY OF IRELAND (MOFFATT, J., Ed.): Employment Law, $3^{\mathrm{a}}$ ed., Oxford (Oxford University Press), 2011.

MAYNOOTH UNIVERSITY: Parental \& Force Majeure Leave Scheme, 2013.

NICHOLLS, K.: Europeanizing responses to labor market challenges in Greece, Ireland, and Portugal: the importance of consultative and incorporative policy-making, Tesis doctoral, Indiana (Universidad de Notre Dame), 2007.

OJEDA AVILÉS, A.: Derecho Trasnacional del Trabajo, Valencia (Tirant lo Blanch), 2013.

PÉREZ DEL RIO, T: “El principio de igualdad de trato y la prohibición por razón de sexo en el Derecho Comunitario", en AA.VV.: Mujer y Trabajo, Albacete (Bomarzo), 2003.

PRIETO PADÍN, P.: "Excedencia por cuidado de hijos y familiares: compatibilidad con el trabajo por cuenta propia o ajena y competencia desleal", RTSS (CEF), núm. 391, 2015, págs. 101-132.

RODRÍGUEZ ESCANCIANO, S.: "La excedencia por razones familiares: una realidad jurídica necesitada de mayor protección social", Anuario da Facultade de Dereito da Universidade da Coruña, núm. 11, 2007. 
SÁNCHEZ-RODAS NAVARRO, C.: La excedencia por cuidados de familiares. El régimen jurídico de los cuidadores no profesionales, Valencia (Tirant lo Blanch), 2008.

SMITH, I. Y BAKER, A.: Smith \& Wood's Employment Law, $11^{\mathrm{a}}$ ed., Oxford (Oxford University Press), 2013.

WEISS, M.: “Convergence and/or divergence in Labor Law systems?: A European perspective", Comparative Labor Law \& Policy Journal, Vol. 28, 2007. 